\title{
Research on dust explosions at the University of Michigan
}

\author{
C. W. Kauffman, M. Sichel and P. Wolanski* \\ The University of Michigan, Ann Arbor, MI 48109-2140 (USA)
}

\begin{abstract}
Dust explosion research carried out at the University of Michigan during the last two decades has been summarized. Significant results are presented on the smoldering combustion of dust heaps, turbulent combustion of premixed dust clouds, entrainment and combustion of layered dust, and on shock wave ignition of particles and shock wave initiated detonative combustion. Also, information on the detonation of hybrid mixtures and gaseous mixtures containing nonreactive particles is given.
\end{abstract}

\section{Introduction}

The rapid development of powdered material and products as applied to modem technology has significantly increased the explosion hazards in industry, since many fine metallic and organic materials are very explosive substances. The explosion of dust mixtures is, however, not a new problem. It first emerged many years ago when very violent dust explosions caused significant human and proper losses in mines and in the grain industry [1-4].

Combustible dust can react with air or with other gaseous oxidizers in three different modes: during smoldering it can be slowly oxidized and propagate with velocities of $\mathrm{mm}$ or $\mathrm{cm}$ per hour; it can burn in the deflagration mode with velocity ranging from $\mathrm{cm} \mathrm{s}^{-1}$ to hundreds of $\mathrm{m} \mathrm{s}^{-1}$; or it can burn in the detonating mode with a velocity of $\mathrm{km} \mathrm{s}^{-1}$.

Each of these modes can be very dangerous and can result in great human and property losses. A great human and property loss due to smoldering combustion of grain dust occurred in the huge grain elevator in Kuybyshev, USSR, where smoldering combustion of grain started in early 1988 and continued until 1990. It caused several explosions, killing at least four people, and created a very large environmental problem.

Deflagrative combustion of dust mixtures is the most frequent cause of explosive damage in industry and mining, so the greatest interest is always focused on this mode of dust mixture combustion. However the most violent combustion can occur during the detonative mode of combustion [5-12]. There is growing evidence

*Visiting research scientist. Permanent address: Warsaw University of Technology, OO-65 Warsaw, Poland. that detonative combustion of dust may occur relatively easy, and simultaneously there is a growing number of incidents of the reported detonative combustion of dust-air mixtures [13-19].

In this paper we will present the contributions of the University of Michigan to the investigations of these problems.

\section{Smoldering combustion of dust mixtures}

The smoldering combustion of dust is a slow, nonflaming, oxidation process limited by the rate of oxygen diffusion through the dust. It can be initiated by a hot surface beneath the dust layer, by a hot object entrained within a dust layer, or by self ignition. Once initiated, smoldering combustion can propagate through a dust bed, and under favorable conditions it can change to glowing, flaming, and even explosive combustion of the dust.

Experiments on the smoldering combustion of a dust layer carried out at the University of Michigan were directed at evaluation of the critical conditions necessary for ignition, studying the influence of convective flow above the layer surface on the reaction front propagation, and at the conditions for transition to glowing and flaming.

Experiments were carried out in a specially arranged wind tunnel, Fig. 1. The tunnel has a square crosssection with a dimension of $0.61 \mathrm{~m}$. The smoldering box is attached to the tunnel bottom. Inside this box, which has insulated walls, the dust is placed, and a set of thermocouples and an ignition source are installed. Layer density can be adjusted when the dust is placed in the box. Flow velocity can be changed by adjusting 


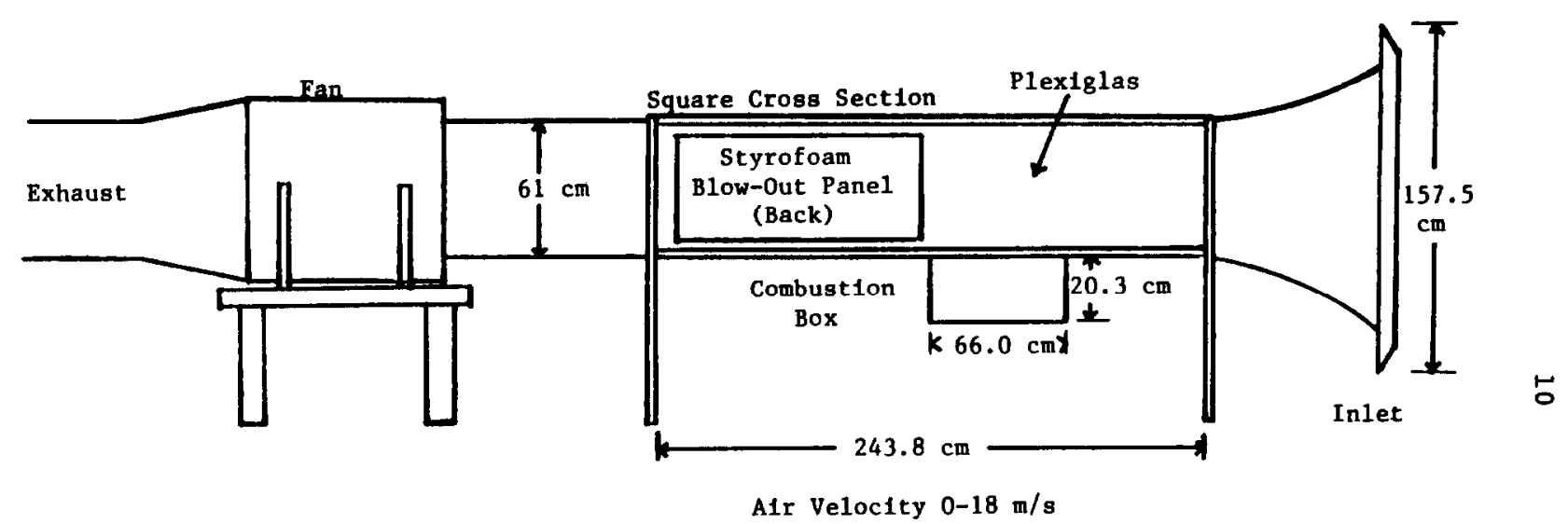

Fig. 1. The University of Michigan wind tunnel facility for the study of the smoldering combustion of dust.

the fan speed and by the setting of a damper. All measurements are controlled and recorded by the data acquisition system connected to a PC computer. More details concerning this experimental set-up can be found in [20].

It was found that the ignition energy for dust in the layer depends very much on the ignition source power and location. Also the convective flow above the surface layer influences the ignition. The typical dependence of the minimum ignition energy on the specific surface power of the ignition source is shown in Fig. 2. Ignition of dust in the layer has a statistical nature. The probability of ignition thus depends on the specific surface energy of the igniter and also on the total energy. This is shown in Fig. 3.

Following ignition, the smoldering front propagates through the dust bed. The smoldering velocity depends

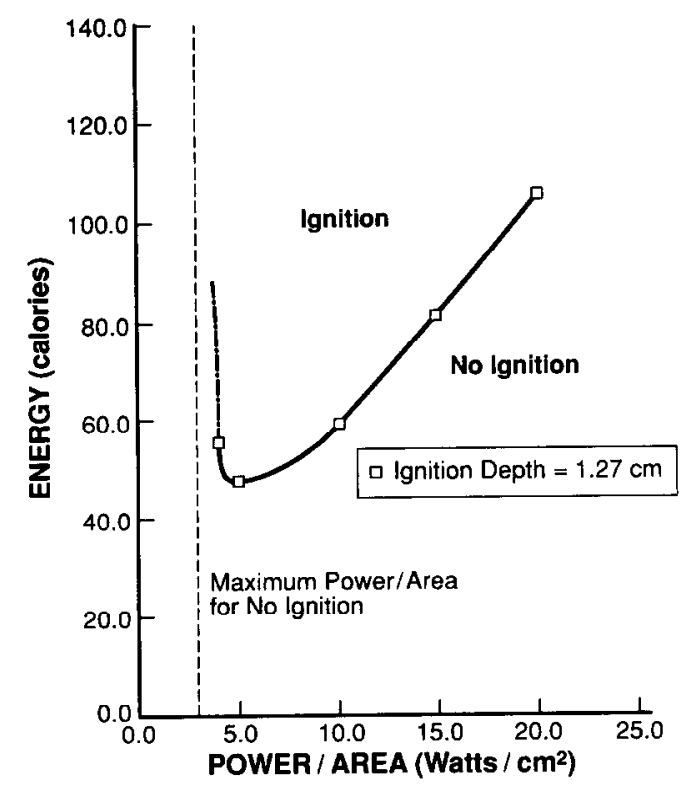

Fig. 2. The minimum ignition energy for a grain dust layer as a function of ignition source power [20].

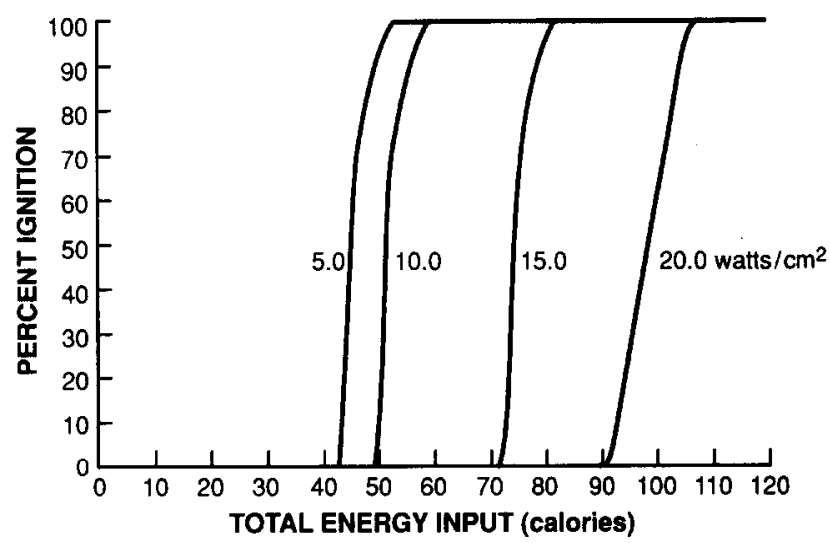

Fig. 3. Probability of the ignition of grain dust in a layer as a function of total energy input, for different specific surface power of the igniter [20].

very strongly on the convective flow direction and velocity, and on the bed arrangement (dust packing density, or layer porosity). In general, the air flow over the layer surface increases the smoldering propagation velocity in grain dust by 2 to 2.5 times. The typical propagation velocity for organic particles is in the order of $10^{-5}-10^{-4} \mathrm{~m} \mathrm{~s}^{-1}$. Convective flow can increase the propagation velocity by more than an order of magnitude.

In some circumstances smoldering combustion of dust can change to glowing or flaming. Glowing or flaming occurs on the surface of the dust bed. Generally the transition time to glowing and flaming increases with increasing bed density, but it also depends on the igniter location and the bed porosity (structure of bed material). Typical data for the transition time in 'bee's wings' (a material derived from corn) and in wood shavings is presented in Fig. 4. Closer location of the igniter to the surface usually decreases the time necessary to obtain flaming combustion. The biggest influence, however, is from the convective flow. Relatively small velocity 


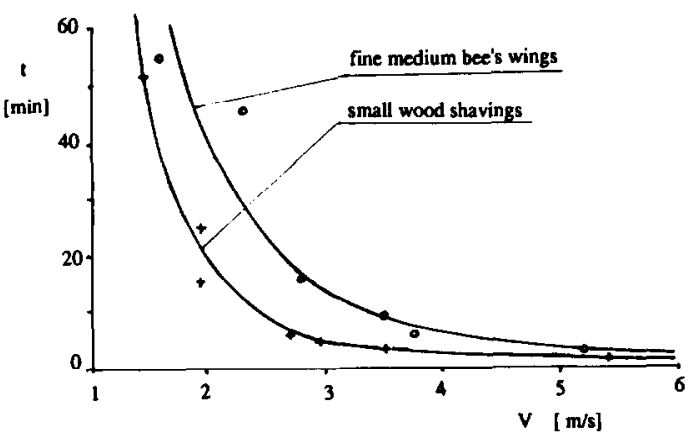

Fig. 4. Transition from combustion to glowing for different dusts [22].

increases can lower the time necessary for the initiation of flaming by more than an order of magnitude.

Smoldering combustion is controlled by heterogeneous oxidation on the particle surface, and by the processes of heat and mass transfer through the bed. The bed density (porosity) influences the heat and mass transfer processes, while the specific reactive surface is only one of the factors controlling the heat release. The reaction wave spreads when the conductive and convective heat losses are balanced by the heterogeneous heat release. The conductive heat loss depends basically on the bed properties, while convective losses depend on bed porosity (density) and on the induced flow velocity. In a large, well insulated bed (as for instance in grain elevators or in a large coal pile), smoldering combustion can be initiated due to a self ignition processes, and it can propagate undetected for a long time. It should be mentioned that smoldering combustion can proceed even for a local oxygen concentration in the bed as small as $1 \%$.

It should be noted also that, under actual conditions, the smoldering, glowing or flaming dust bed can relatively easily result in an explosion. Weak blast waves in an unconfined space can transform such a layer to a large 'fire-ball', or in a confined space to a very dangerous explosion.

\section{Combustion of dust mixtures}

Understanding of dust combustion is the key element needed to understand the nature of dust explosions, since the combustion rate is one of most important controlling factors in all explosions. During the last two decades, much fundamental work has been focused on this problem.

It is most important to understand the influence of turbulence intensity and, probably, scale on the flame propagation velocity. For gaseous mixtures, the velocity of turbulent combustion can be related to the laminar burning velocity and the turbulence parameters. The laminar burning velocity for gaseous mixtures can be easily measured, so that the turbulent burning velocity may be predicted. In contrast to gaseous flames, laminar dust flames are practically nonexistent, since the presence of dust in the gaseous oxidizer (at normal gravity conditions) will always result in the generation of some turbulence (due to sedimentation of the dust). Turbulence is thus an inherent property of dust mixtures. In practice dust mixtures are created by the interaction of a turbulent flow with dust, so in such cases the initial turbulence level can be very high. For these reasons only so called quasi-laminar dust flames can be obtained. Even these flames can generate additional turbulence due to the burning of nonuniformly dispersed dust clouds [23].

It was recognized very early that high turbulence intensity increases dramatically the rate of dust combustion (explosion), but the early studies were carried out only concerning the influence of unquantified turbulence intensity on the rate of pressure rise [4], [24-27]. Such studies and others lead to the introduction of the Cubic Law factor, Kst, which is by definition equal to the measured maximum rate of pressure rise in the confining vessel times the volume of the vessel raised to the one third power, which relates the rate of pressure increase to the arbitrarily chosen and unknown turbulence intensity. Thus, Kst is an arbitrarily chosen factor, and it depends very strongly on the initial and boundary conditions. It is especially sensitive to the shape and size of the explosion chamber, initial turbulence (scale and intensity), uniformity or nonuniformity of the created mixture, and the type of ignition source. For these reasons the Kst factor evaluated for the same dust can vary very significantly if it is evaluated in different test stands, in different laboratories, or even by different researchers. A much better and more objective comparison of the explosive severity of dust mixtures can be made by the comparison of the flame propagation velocity measured under controlled turbulence intensity. For this reason a special jet-stirred reactor was built at the University of Michigan to study constant volume turbulent flame propagation [28].

A schematic diagram of the jet-stirred reactor is shown in Fig. 5. The combustion vessel is a $1.22 \mathrm{~m}$ diameter sphere, designed to withstand $10 \mathrm{~atm}$ pressure. It is also possible to study in this vessel the combustion of homogeneous gaseous mixtures, as for instance, a methane-air mixture. The combustible mixture is supplied to the chamber through six 1 inch diameter hoses of equal length connected from the inlet flow divider. These inlets are positioned symmetrically at the north and south poles and at $90^{\circ}$ along the equator in order to create uniform isotropic turbulence within the sphere. The outlet hoses are located in each of eight quadrants of the sphere and are then manifolded into the exhaust pipe. Two ball valves are located at the inlet and at 


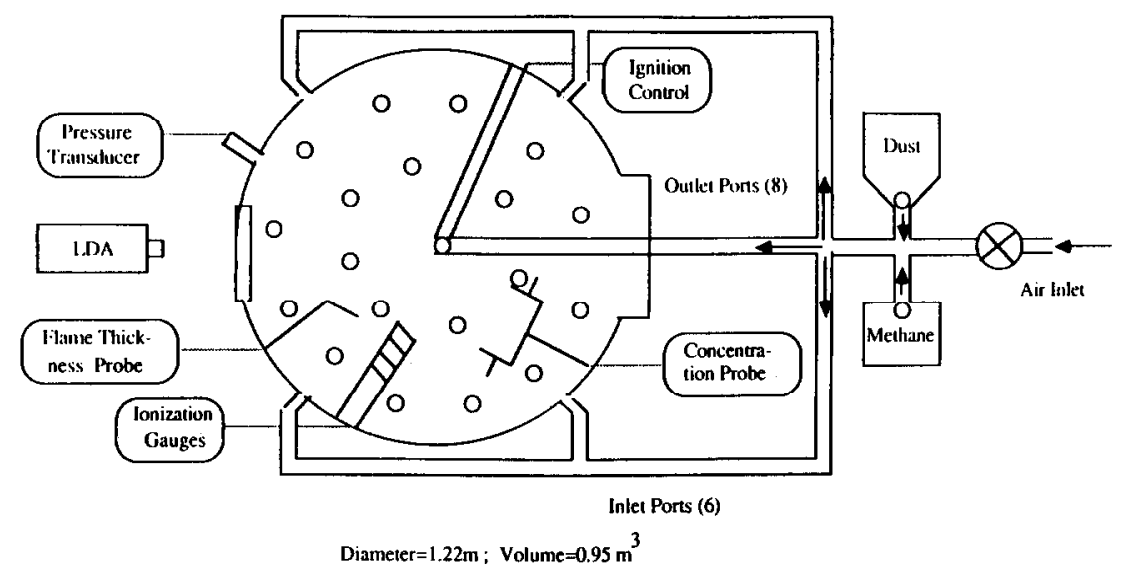

Fig. 5. Jet-stirred factor.

the exhaust manifolds. The dust mixture of required concentration and turbulence intensity is created by mixing the dust supplied from a dust feeder with the inlet air. The selection of the feeding rate and air flow rate make it possible to control the dust concentration and the turbulence intensity independently. The dust air mixture is passed through the sphere under steady state conditions for a few seconds. Then both the inlet and exhaust ball valves are closed and ignition is initiated. In most cases an exploding wire of $100 \mathrm{~J}$ energy with $7.8 \mathrm{~g}$ of gun powder located at the center is used as the ignition source.

The dust concentration is measured by a light attenuation probe and turbulence intensity by both laser and hot wire anemometers. Ionization probes allow measurement of the flame propagation velocity, and a photodiode is used to measure the flame thickness. A pressure transducer is used to monitor the pressure variation during the explosion, required to find the combustion velocity and ultimately to normalize the burning velocity to atmospheric conditions. A more detailed description of the apparatus and experimental techniques can be found in [28].

This experimental apparatus allows measurement of the influence of turbulence intensity up to $\mathrm{u}^{\prime}=4.2 \mathrm{~m}$ $\mathrm{s}^{-1}$ on the explosion parameters. Much data for different dust mixtures was obtained. Typical data obtained are shown in Figs. 6 to 10. Increased turbulence has a relatively small effect on the maximum explosion pressure (Fig. 6), but a rather significant effect on the rate of pressure rise (Fig. 7). Since the rate of pressure rise depends directly on the combustion velocity there is a similar influence here. In the sphere, the flame spreading velocity is measured by the ionization probes. This velocity is the result of the burning velocity and of the convective flow velocity generated ahead of the flame front by the expanding combustion products. So to get the burning velocity the convective component should be subtracted from the measured flame velocity.

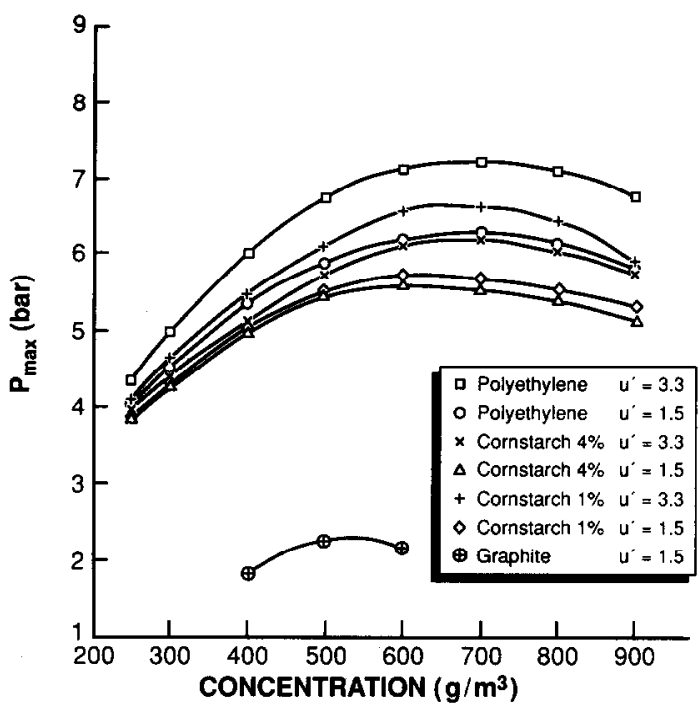

Fig. 6. Effect of turbulence on $P_{\max }$ for different dusts, and different moisture content of cornstarch dust.

To calculate the convective flow velocity, the flame front position, the pressure, and the rate of pressure rise should be known. Then the burning velocity of the dust flame can be calculated $[21,29,30]$. Such calculations allow one to obtain the burning velocity at the given pressure. Since the pressure in the sphere is continuously changing, measurement of the burning velocity at different pressures is necessary for the extrapolation of results to atmospheric conditions. Fig. 8 shows the burning velocity corrected to atmospheric pressure for different dusts and different turbulence intensities.

From the measured burning velocities obtained at different turbulence intensities, the laminar burning velocity for dust mixtures can be obtained by extrapolation. Corrected laminar burning velocities for a few different dust mixtures are presented in Fig. 9. Laminar or quasi-laminar burning velocities cannot be measured directly as the dust would not remain in suspension 


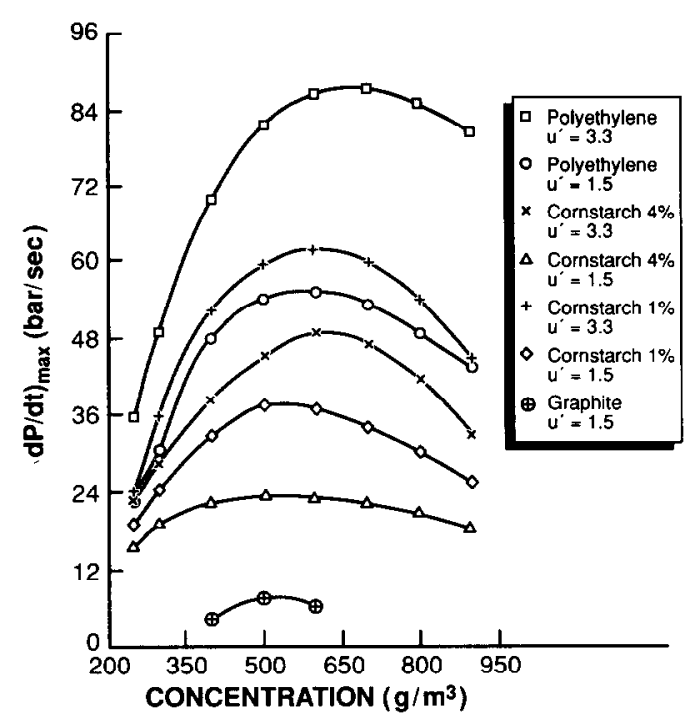

Fig. 7. Effect of turbulence on $(\mathrm{d} P / \mathrm{d} t)_{\max }$ for different dusts, and for different moisture content of cornstarch dust.

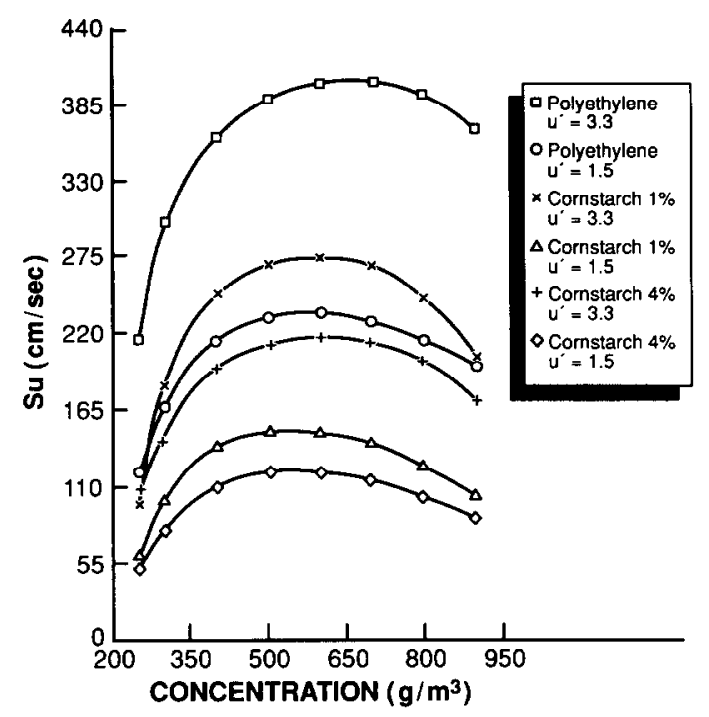

Fig. 8. The effect of turbulence on corrected burning velocity for different dusts, and for cornstarch dust of different moisture content.

under such conditions. For the cornstarch dust the influence of moisture content on burning velocity can be seen. It should be noted that the corrected laminar burning velocity obtained for different organic dusts are of the same order as the burning velocity of a methane-air mixture. The thickness of the flame is actually much bigger for a dust than for a gas.

The turbulence also has a major influence on the minimum ignition energy of dust mixtures. As expected, increasing turbulence intensity increases the minimum energy level necessary for ignition. Figure 10 presents data obtained for cornstarch at different ignition source powers (exploding wire) at different turbulence intensities.

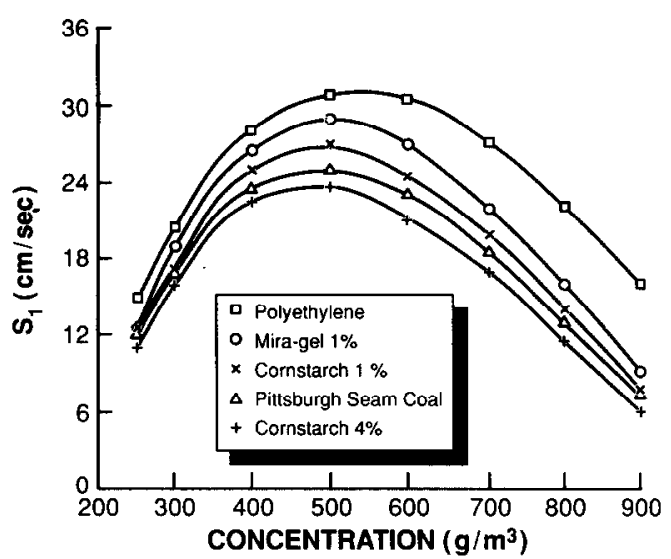

Fig. 9. Corrected burning velocity for different dusts (cornstarch dust of different moisture content).

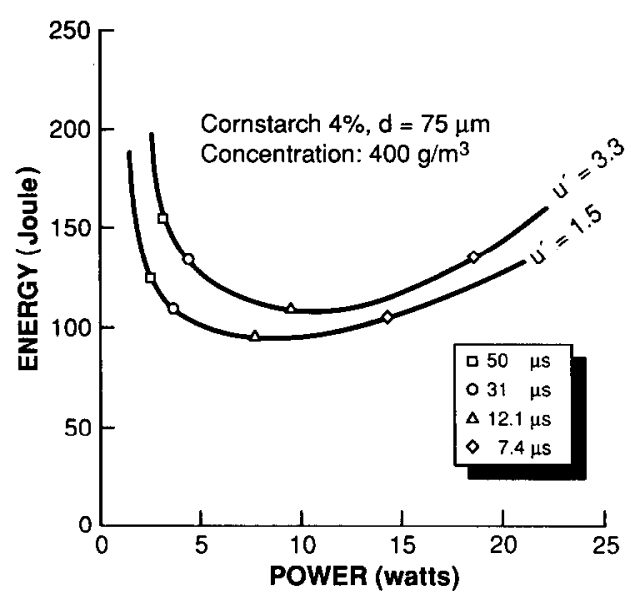

Fig. 10. Minimum ignition energy for cornstarch as a function of ignition source power for different turbulence intensities.

Much data concerning the rate of pressure rise was obtained during the last decade in the 201 sphere, so it was of great interest to compare the turbulence intensity and structure generated in the 9501 sphere to the turbulence generated in the small sphere [31]. It was found that the turbulence characteristics are more constant in the larger sphere. In the 9501 sphere, turbulence intensity in stationary flow is about twice as large as in nonstationary flow. After interruption of the flow, the turbulence intensity decays relatively slowly during the first $0.5 \mathrm{~s}$ and then more rapidly while the turbulence scale increases smoothly even up to $1 \mathrm{~s}$ after dust ignition. By contrast, dissipation processes in the small sphere are much faster. Turbulence intensity is highest immediately after dust dispersion and decreases rapidly to less than $10 \%$ of its maximum value in $150-400 \mathrm{~ms}$. It is obvious that the turbulence can be more easily controlled with less transient effects in the big sphere. 


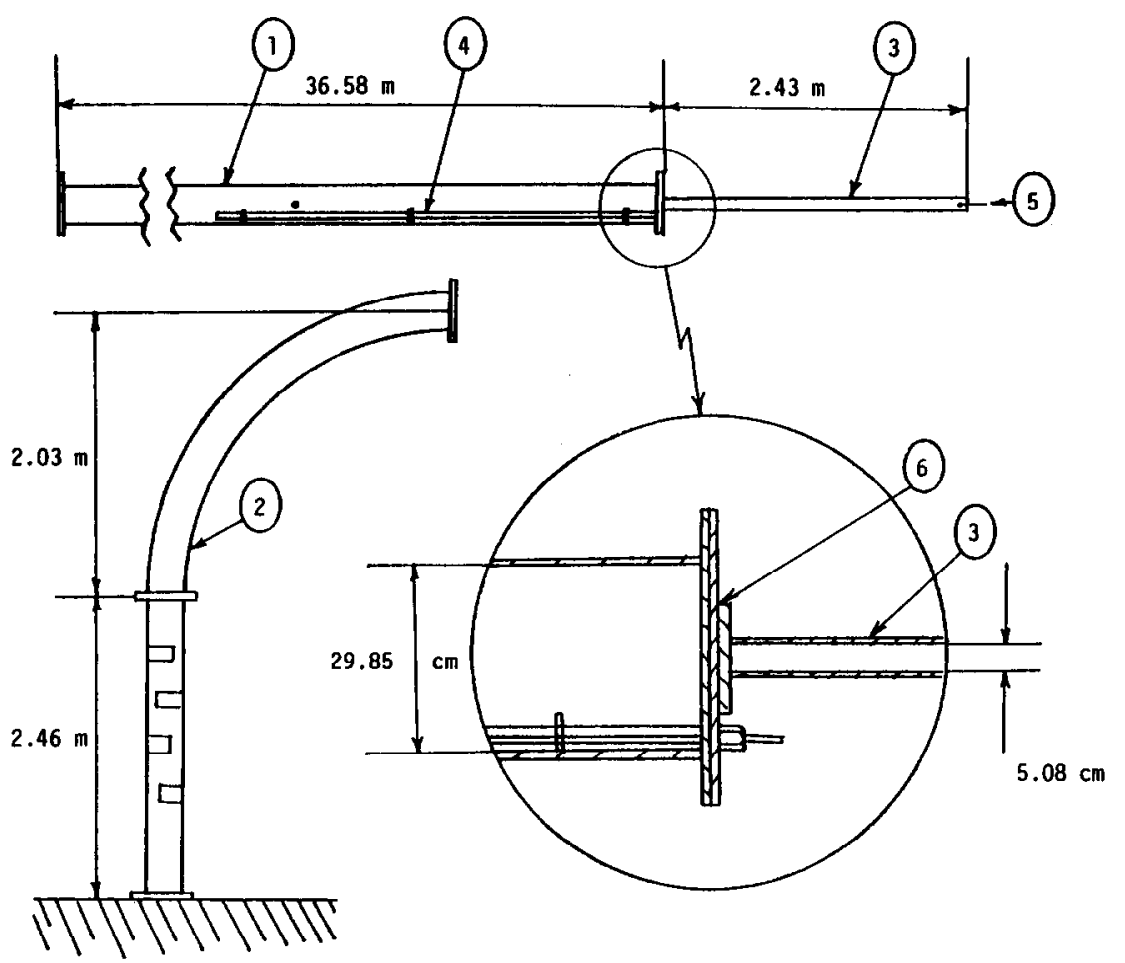

Fig. 11. Flame Acceleration Tube (FAT): (1) main tube; (2) exhaust system; (3) initiator (auxiliary detonation tube); (4) dust dispersion system at the beginning; (5) glow plug; (6) mylar diaphragm.

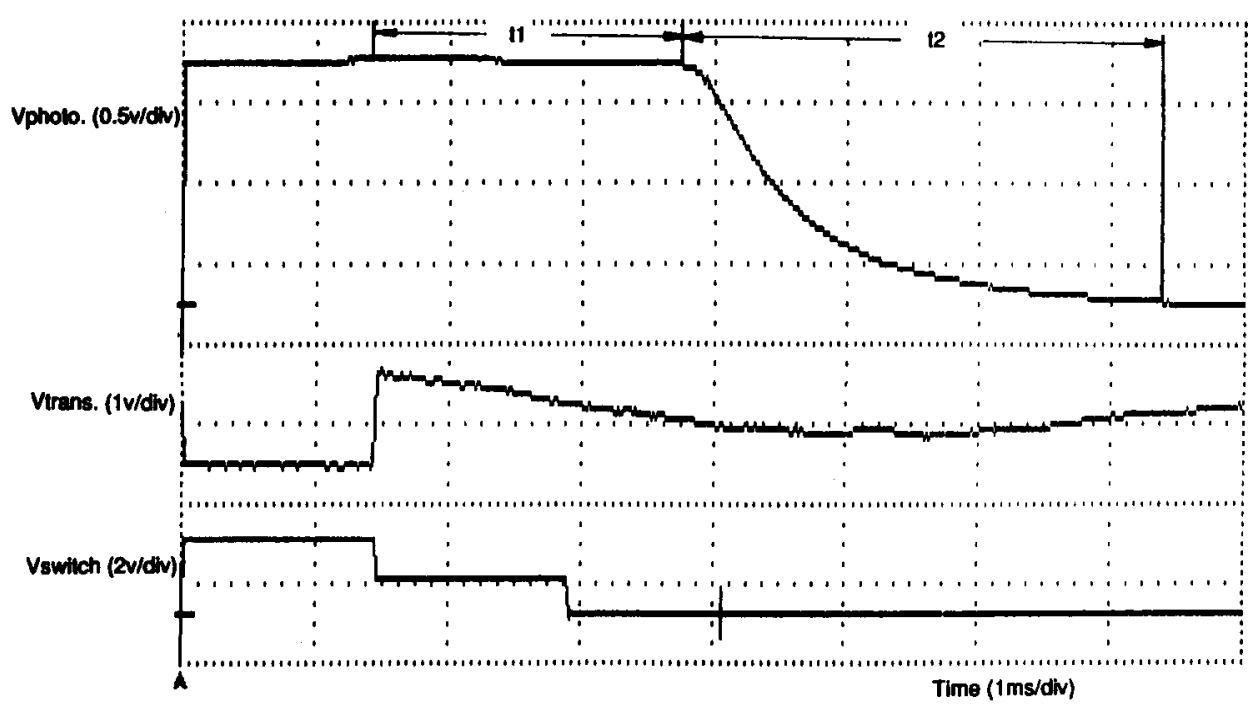

Fig. 12. The effect of the passage of a $M=1.4$ shock wave on the suspension of a $4.0 \mathrm{~mm}$ layer of corn starch with shock wave velocity and intensity indicated as well as reflected light intensity.

In the above experiments the generated turbulence was of relatively small scale (the order of $\mathrm{cm}$ ) and low intensity, but in real industrial conditions much larger scale turbulence probably controls the flame propagation. For that reason explosion research must also be carried out under conditions closer to those which are encountered in industry.
The work carried out in this sphere is now focused not only on measurement of burning velocities, but also on more detailed measurements of the turbulent flame structure, since a better understanding of the mechanism of turbulent flame propagation in the dust mixture is essential to understand the nature of all dust explosions. 


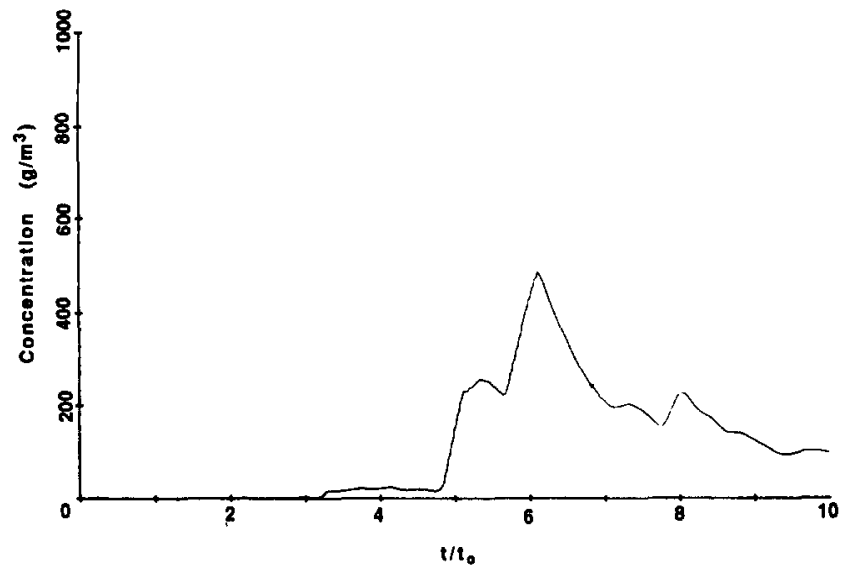

Fig. 13. Typical variation of dust concentration in the tube center as a function of time.

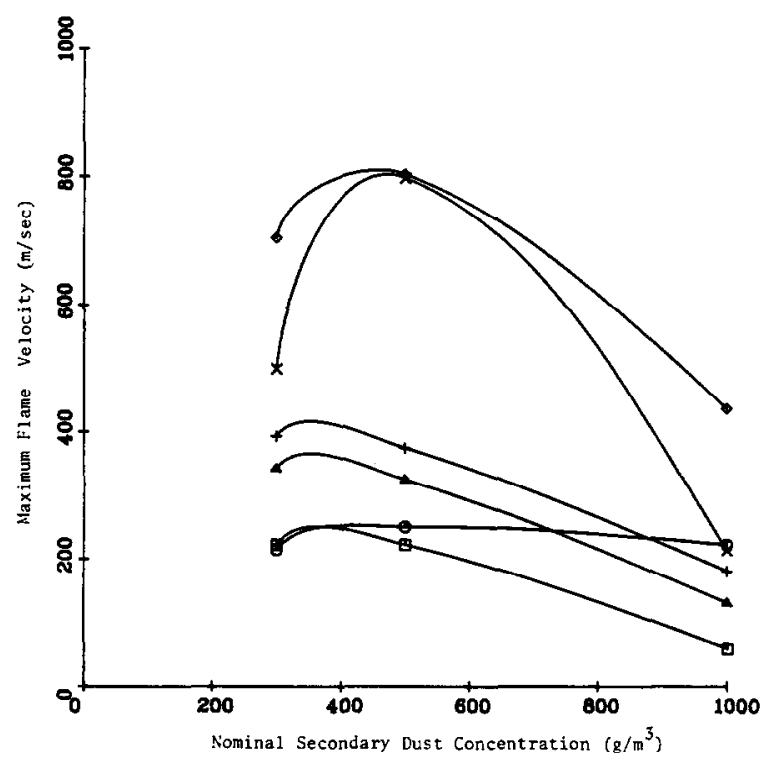

Fig. 14. The effect of the layer thickness and grids on the maximum flame velocity. Moist baghouse dust under $75 \mu \mathrm{m}$, primary conc. $=1000 \mathrm{~g} \mathrm{~m}^{-3}$, initiator pressure $=1.013 \times 10^{5} \mathrm{~N} \mathrm{~m}^{-2}$; $\diamond$, thin layer for $24.39 \mathrm{~m}$ - with grids; $\times$, thin layer for 24.39 m - without grids; +, medium layer for 36.58 m - with grids; $\Delta$, medium layer for $36.58 \mathrm{~m}$ - without grids; $O$, thick layer for $36.58 \mathrm{~m}$ - with grids; $\square$, thick layer for $36.58 \mathrm{~m}$ - without grids.

\section{Accelerating dust flames}

Higher turbulence intensity can be obtained when a flame accelerates in a tube. In many gaseous mixtures, the flame accelerating in a tube can eventually change to a detonation. It is thus of great interest to find how the flame will accelerate, particularly to layered dust flames in relatively long ducts.

Experiments on flame acceleration in long ducts have been carried out for a long time, especially for different coal dusts, but also for many other organic or inorganic

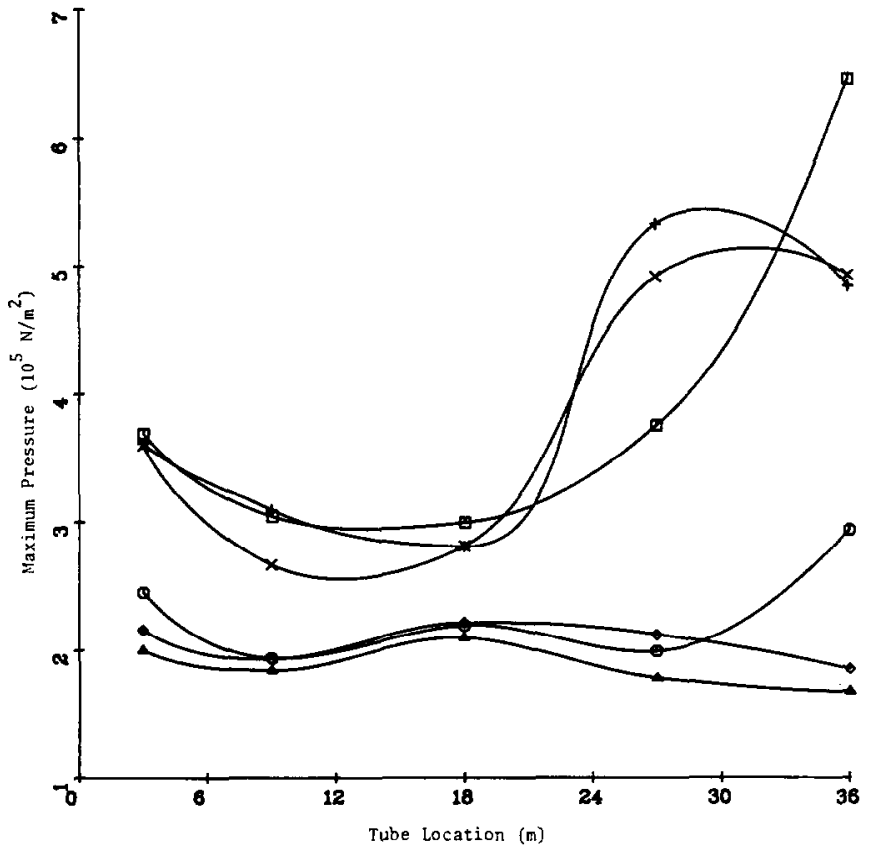

Fig. 15. Maximum explosion pressures for different dusts and different layer thicknesses. Primary conc. $=500 \mathrm{~g} \mathrm{~m}^{-3}$, secondary conc. $=366 \mathrm{~g} \mathrm{~m}^{-3}$, initiator pressure $=1.013 \times 10^{5} \mathrm{~N} \mathrm{~m}^{-2}$, bead length $=24.39 \mathrm{~m} ; \square$, dry Mira gel - thin layer; $O$, wet Mira gel - thin layer; $\triangle$, dry Mira gel - thick layer; +, dry PFP thin layer; $x$, wet PFP - thin layer; $\diamond$, dry PFP - thick layer.

dusts. Such experiments range in scale from small laboratory tubes to the big (real scale) surface or underground mine galleries. These latter ones are related directly to explosion safety and are aimed at finding effective countermeasures to prevent or suppress uncontrolled explosions in mining and in industry. The results of these studies can be found elsewhere [3-4].

For studies of flame acceleration resulting from layered combustible dusts, a special Flame Acceleration Tube (FAT) was constructed at the University of Michigan. The tube is of $0.305 \mathrm{~m}$ internal diameter and was initially $36.6 \mathrm{~m}$ long, but was later extended to $70 \mathrm{~m}$. A schematic diagram of this tube is shown in Fig. 11 [32].

Dust can be deposited inside the tube in layers of three different widths: $13 \mathrm{~mm}$ layer (called thick layer) $90 \mathrm{~mm}$ layer (called medium layer) and a thin layer for which the dust is uniformly distributed inside the tube using a centrifugal blower. The layers are of varying thickness to give different dust concentrations. However, the entrainment process is sensitive to both thickness and width so the same concentration of layered dust per unit length will not give the same concentration of suspended dust. Ignition is provided by a small auxiliary detonation tube filled with a hydrogen-oxygen mixture. Just in front of the initiator, a $3.66 \mathrm{~m}$ long $V$-shaped dispersion system is placed, to provide dust dispersion in the first part of the tube prior to the 


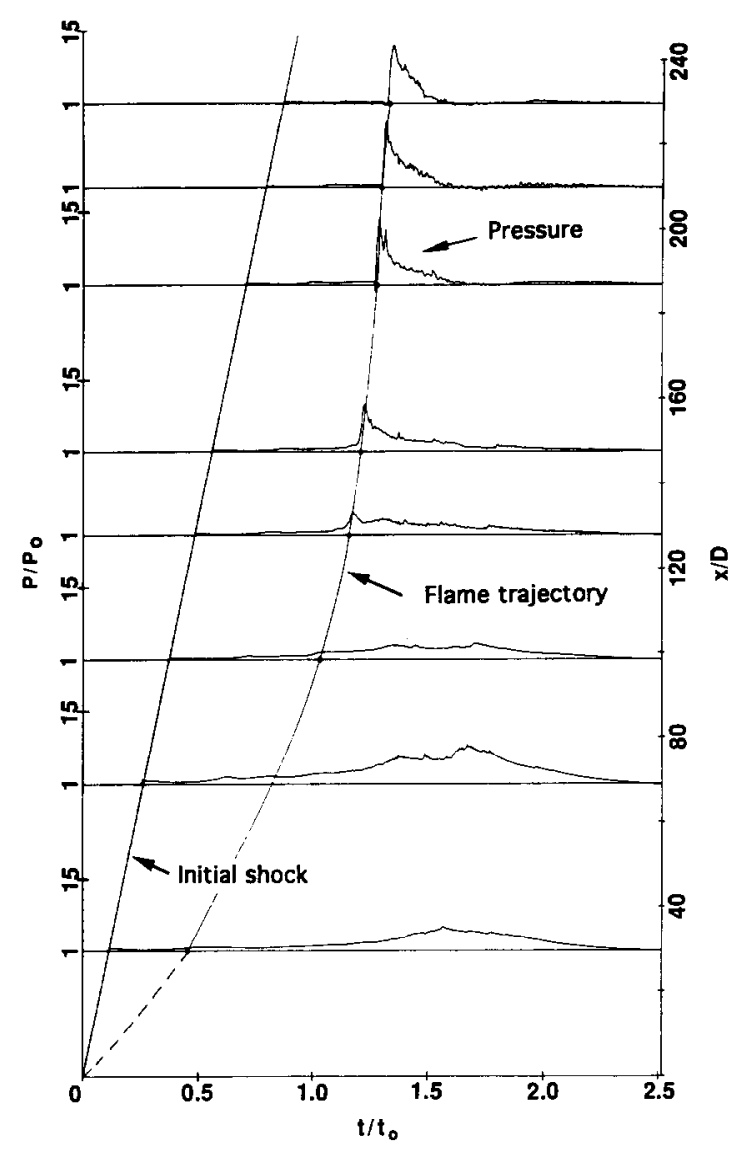

Fig. 16. Typical pressure histories at the different tube locations, and the flame front position for the case of flame acceleration to a quasi-detonation in a medium corn dust layer with $1 \%$ addition of Cabosil. Corn concentration in the layer: $500 \mathrm{~g} \mathrm{~m}^{-3}$, layer length: $51.5 \mathrm{~m}$.

initiation of the $\mathrm{H}_{2}+1 / 2 \mathrm{O}_{2}$ detonation in the auxiliary detonation tube. The explosion of a hydrogen-oxygen mixture provides the precursor shock which is responsible for the slight initial dispersion of the dust layer and the initiation of the primary dust explosion (combustion of the dust predispersed in the first $3.66 \mathrm{~m}$ of the tube). As a result of this primary explosion the flame accelerates in the tube.

Dust dispersion is monitored by a concentration probe, and a high speed camera can be used for the qualitative observation of the variation of dust dispersion with time. Direct pictures give general information about the dust dispersion process while the optical probe measures the dust concentration variation in the tube center. Quantitatively information such as rate of entrainment may be obtained from backscattered and transmitted laser light as layered dust behaves optically differently from suspended dust [33]. The interaction of a $4.0 \mathrm{~mm}$ dust layer with an $M=1.4$ shock wave is shown in Fig. 12. The relaxation time for the dust layer after the passage of the pressure increase can be clearly noted $(t 1)$ as well as the steady erosion of the dust

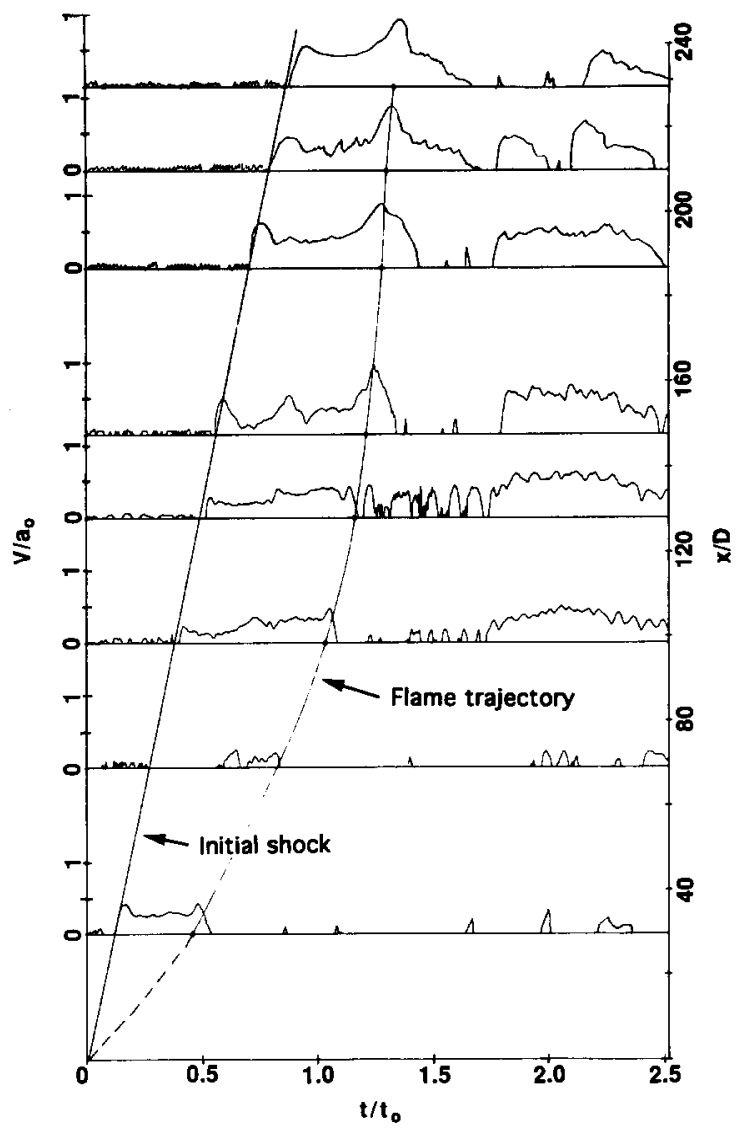

Fig. 17. Mach number of flow at different tube locations and the flame front trajectory for corn a dust layer explosion. The same condition as in the previous figure.

from the layer as indicated by the decrease in the intensity of the reflected (diffused) light ( $t 2$ ). From Fig. 13 one can see that the precursor shock causes initial suspension of the dust into the tube center. At this stage the dust concentration in the tube center is relatively low, but it increases dramatically just before flame arrival, and then the dust concentration decreases due to burn out of the dust particles.

Static and dynamic pressures and temperature are measured at eight different locations along the tube. Additionally the temperature of burning dust particles is measured by a four wavelength pyrometer. At the end of the tube a special exhaust section provides for the ventilation of the explosion. The whole system is controlled by an IBM 9000 microcomputer. The suitably amplified outputs from all instruments are fed into a 32-channel analog-digital converter. After each run all data is processed by the microcomputer. A detailed description of the whole system can be found in [34-35].

In the early stage of research, the tube had a length of $36.6 \mathrm{~m}$. Some results obtained from these studies are presented in Figs. 14 and 15. In Fig. 14 the maximum flame velocity is presented as a function of the nominal 


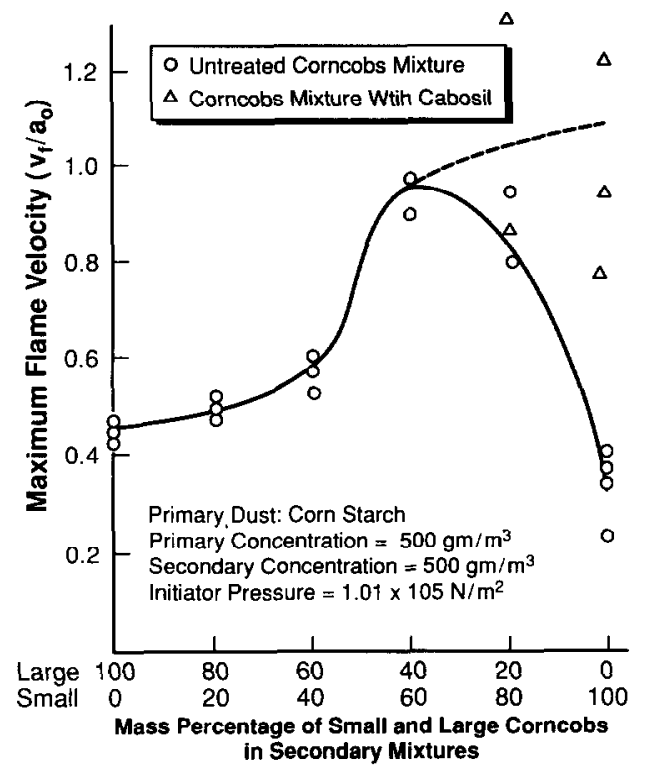

(a)

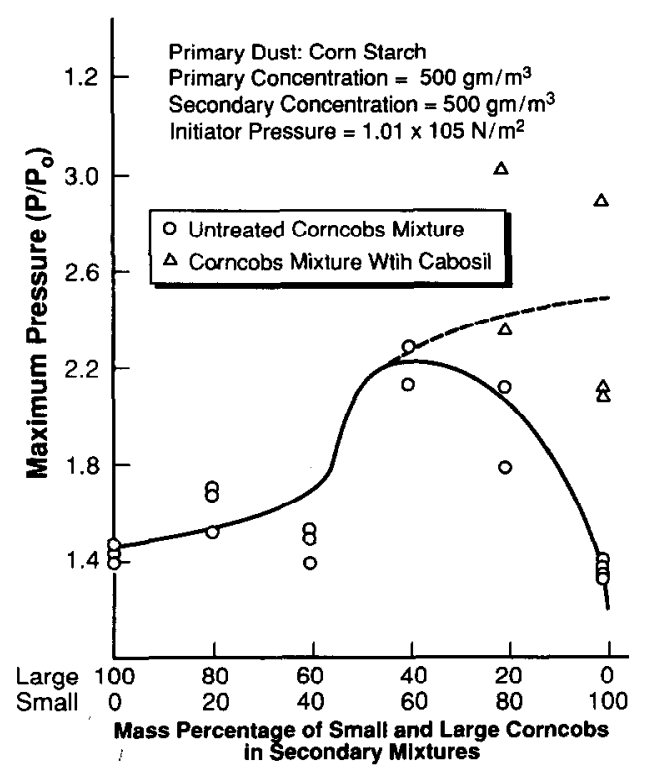

(b)

Fig. 18. Maximum velocity (a), and pressure (b), obtained for different bimodal particle percentage compositions. Corn starch dust concentration in the layer: $0.5 \mathrm{~kg} \mathrm{~m}^{-3}$.

dust concentration in the tube for different arrangements. A thin layer without grids results in the maximum propagation velocity while for the medium and thick layer the grid almost always accelerates the flame propagation. Fig. 15 shows the maximum pressure as a function of downstream location. For slowly accelerating flames the maximum pressures remain nearly constant along the whole tube length, but for a rapidly accelerating flame the maximum pressure is observed at the end of the dust layer or even beyond it. This is due to the process of dispersion of the dust in the convective flow ahead of the flame; dust can be carried even a dozen meters ahead of the original end of the dust layer. It can be seen that in some cases the highest flame velocities are observed beyond the original end of the dust layer. In the short tube the maximum explosion pressures did not exceed 8 bars, but for the $70 \mathrm{~m}$ long tube the maximum explosion pressure associated with layered dust explosion exceeded 26 bars.

The maximum pressure in the FAT is always related to the flame propagation velocity. This ratio is nearly linear for deflagrative combustion and becomes highly nonlinear when the flame accelerates to a quasi-detonative combustion process. For the latter case the maximum pressure rise is observed in the region where the transition to quasi-detonation occurs, in the region of the so-called 'explosion within the explosion'.

Typical pressure profiles recorded at different locations and the flame front trajectory in the tube are shown in Fig. 16. It can be seen that the flame accelerates continuously until it reaches quasi-detonation velocity. Transition to quasi-detonation occurs between $45 \mathrm{~m}$ and $57 \mathrm{~m}$, and then the flame propagates with a velocity of about $1200 \mathrm{~m} \mathrm{~s}^{-1}$. Gas velocity at different tube locations is shown in Fig. 17. Just behind the shock wave generated by the initiator, the gas Mach number is about 0.5 , and it then decreases for some period. Later, the influence of the flame generated flow can be observed, and the gas velocity ahead of the flame increases. Before transition to quasi-detonation the gas velocity increases continuously, and some distance behind the flame front a steep decrease can be found. After transition to quasi-detonation a sharp velocity increase is detected followed by a rapid flow reversal. The reversed flow in the tube is not monitored due to the omni directional measurement of the dynamic pressure. The reverse flow is created by the shock wave reflected from the tube elbow.

Quasi-detonation in the FAT up to now has been observed for corn dust with the addition of Cabosil and for Miragel dust. Propagation velocities are in the range of $1000-1200 \mathrm{~m} \mathrm{~s}^{-1}$, and the associated pressure in the shock front ranges from 9 bar to 12 bar. Much higher pressures are observed in the transition region.

Continuous propagation of a quasi-detonation supported by layered dust is not possible. For continuous propagation of a quasi-detonation or detonative combustion the dust-air mixture should be created ahead of the leading detonation (quasi-detonation) wave. $\mathrm{Ob}$ viously dust must be dispersed by a precursor shock. The precursor shock propagates, however, with a much smaller velocity than the detonative (quasi-detonative) combustion, so when the detonative front reaches the region of undisturbed mixture the detonation (quasidetonation) will fail, and the shock wave will decouple from the associated combustion wave. The flame will 


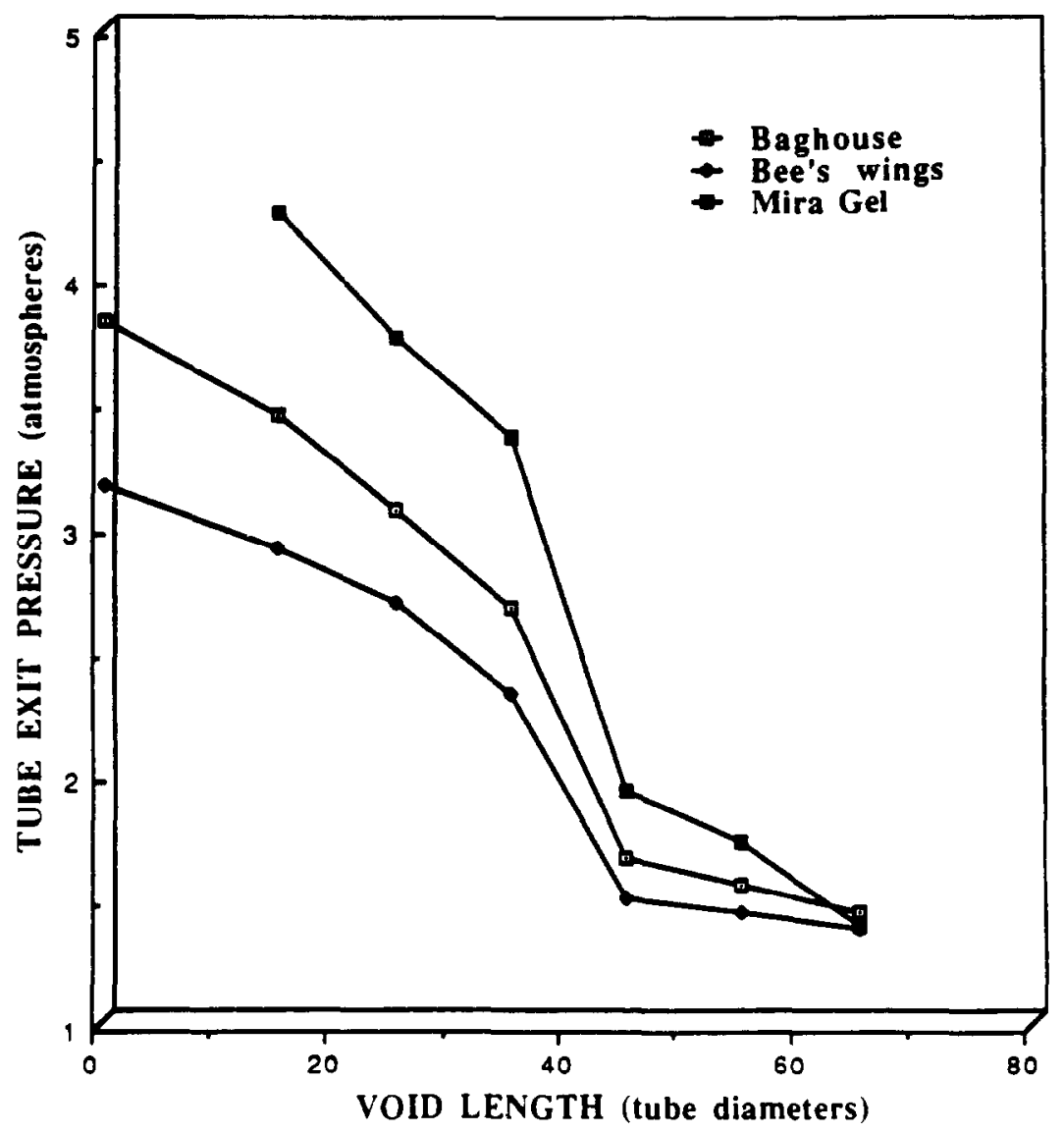

Fig. 19. Effect of voids on the tube exit pressure as a function of dimensionless void length (normalized to tube diameter).

then slow down and the shock will again disperse dust ahead of the flame. The flame will accelerate again and the quasi-detonation (or detonation) from will be reestablished. So in very long tubes one can expect conditions similar to 'a galloping detonation'.

Another interesting study carried out in the FAT tube concerns the influence of a bimodal particle size distribution and also the effect of a dust void on the explosion development [36]. For the bimodal particle experiments, small corn cob material with a diameter of less than $75 \mu \mathrm{m}$ and large particle corn cob material with diameters between $425-800 \mu \mathrm{m}$ were used. For the total dust concentration of $0.5 \mathrm{~kg} \mathrm{~m}^{-3}$ a different ratio between the small and large particles was tested. Also separate experiments for the small and for the large particles were carried out. It was found that the highest propagation velocity and maximum pressure rise occur when the small particles comprise $60 \%$ of the mixture (Fig. 18). However, the addition of Cabosil to the mixture shifts the optimum value to $80 \%$ of the small particles and significantly increases the maximum explosion pressure. This can be explained by the increased dispersive properties of the dust with the addition of the larger particles or the Cabosil.
The effect of a void on layered dust explosions has been studied for three different kinds of dust: baghouse, bee's wings, and Miragel. Baghouse dust is the dust literally removed from the baghouse of a dust collection system at a grain elevator which handled only corn, bee's wings are a red colored flake type material which comes from corn cobs, and Miragel is a commercial starch product. Details are given in [38]. Despite the differences in the explosibility of these dusts, the general influence of the void on the pressure measured at the end of the tube (exit pressure) was the same. It can be seen in Fig. 19 that the exit pressure decreases continuously as the void length increases. When the void reaches approximately 65 tube diameters the explosion is no longer transmitted through the void area. From this data it is difficult to conclude whether the linear distance or number of tube diameters is important in isolating the primary explosion from the secondary explosion of the layered dust. It will probably be a stronger function of the linear distance. The safe void distance will depend on the time of burning of the dust particles and the velocity of the induced flow. So, if burning particles (or still sufficiently hot burned gases) will reach the fresh dust dispersed from the next layer, the newly dispersed cloud can be ignited and the flame 


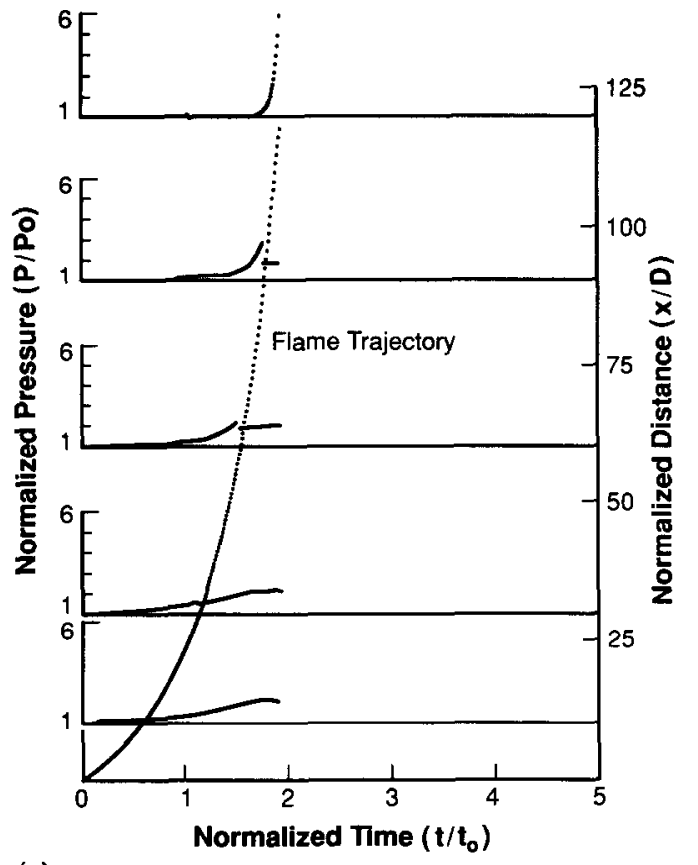

(a)

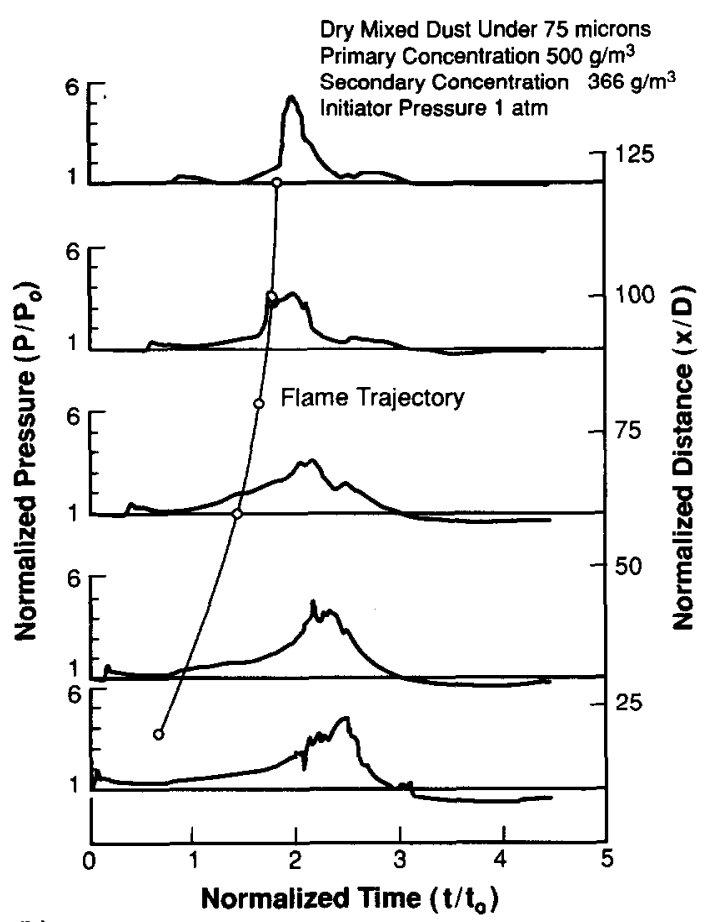

(b)

Fig. 20. Variations of pressure and flame position at different tube locations as a function of dimensionless time (normalized to the time of the shock wave passage through the entire tube); (a) numerical calculations; (b) experimental results.

will start to accelerate again. However, for a more conclusive answer more studies are necessary.

Modeling layered dust explosions is a complex and difficult task, since it involves many nonlinear and nonstationary phenomena. In this case the most im-

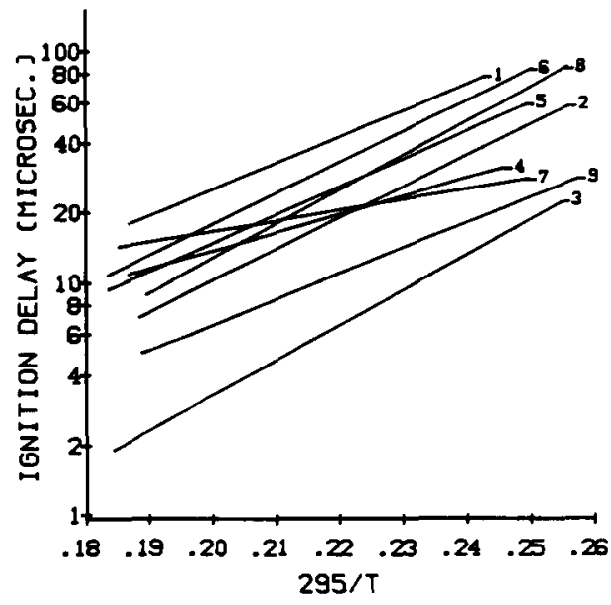

Fig. 21. Ignition delay time of dust particles as a function of (reciprocal) temperature behind the incident shock wave. Lines represent the mean square fit of the experimental ignition delay data. Equivalent activation energy in $\mathrm{kcal}(\mathrm{g} \mathrm{mol})^{-1}, 1$, coal 15.3; 2, graphite 18.2; 3, Oats 18.4; 4, RDX-A* 10.5; 5, RDX-E* 16.4; 6, RDX-E 18.0; 7, diamond* 6.2; 8, coal 18.2; 9, graphite 19.8 . *implies addition of $10 \%$ Cabosil by weight. 1-7 were obtained by inertial injector, 8,9 were obtained by air injection.

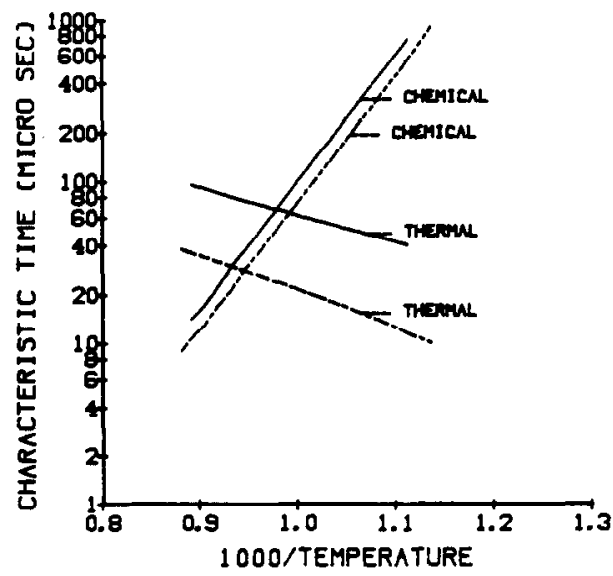

Fig. 22. The variation of characteristic thermal and chemical time of coal particles as a function of inverse particle surface temperature. Coal for $53 \mu \mathrm{m}$ particle, -, mach No. 4.2; - - , mach No. 4.6.

portant and difficult phenomena to model are the entrainment of dust from a surface by the boundary layer flow with the successive mixture formation, and the coupling of the burning velocity with the intensity and scale of the turbulence ahead of the flame. In the first attempt to model such an explosion, the Chi and Perlee model [37] was modified by Srinath [38]. By the incorporation into this model of the submodel of dust dispersion developed by Mirels [39] and the turbulence combustion submodel of Clark and Smoot [40], numerical calculations relating to layered grain dust explosions were possible. Calculations were done for a grain dust size of $49 \mu \mathrm{m}$ and a dust layer loading of $0.5 \mathrm{~kg} \mathrm{~m}^{-3}$. The calculated pressure histories at different 
down strcam locations are given in Fig. 20(a), while experimental results obtained for similar conditions are presented in Fig. 20(b). It can be seen that the initial pressure rise and flame trajectory are comparable, but the subsequent calculated pressure rise did not follow the experimental results closely. This indicates that this model should be improved, and additional work on the problem is in progress.

\section{Shock wave initiated dust combustion}

A shock wave can be the source of ignition for a dust particle or it can initiate detonative combustion of dust mixtures. Studies of such processes has been carried out at the University of Michigan for a long time, and there are many publications on this subject $[13,14,18,41-47]$. Also theoretical investigations and numerical calculations have been pursued for many related problems, [43, 48-50]. Recently a survey paper on this subject matter was written [51], so only a brief general description will be given here.

Ignition of dust particles has been studied experimentally and theoretically at the University of Michigan $[13,41-45,49,50]$. Experiments were conducted in horizontal shock tubes, and the ignition process for particles was analyzed analytically and numerically. Ignition delay data for many different dusts are reported. The most important findings from the experiments are as follows. Many organic and metallic dusts can be easily ignited by a shock wave, some even easier than gaseous mixtures. The size and structure of the dust particle affects the ignition strongly. There is an optimum dust diameter for ignition. A theoretical analysis shows that physical considerations (particle heating) rather than chemical considerations are the most important elements controlling the process of particle ignition.

Typical experimental ignition delay data obtained in the horizontal shock tube are shown in Fig. 21. It can be seen that despite very big differences in dust particles, the data obtained differ little and that the activation energies are of the same order of magnitude. Theoretically calculated thermal and chemical characteristic times for a coal particle subjected to a shock wave of different Mach numbers are presented in Fig. 22. These and other calculations show that, for the conditions of shock wave ignition of a dust particle, the physical process of thermal heating of the particle is the controlling factor in dust particle ignition, so that the global activation energy for ignition is basically very similar for most dusts.

The relatively short ignition delay of many dust particles is due to the peculiar behavior of the dust particles behind the incident shock wave. When a dust particle is subjected to the supersonic flow existing

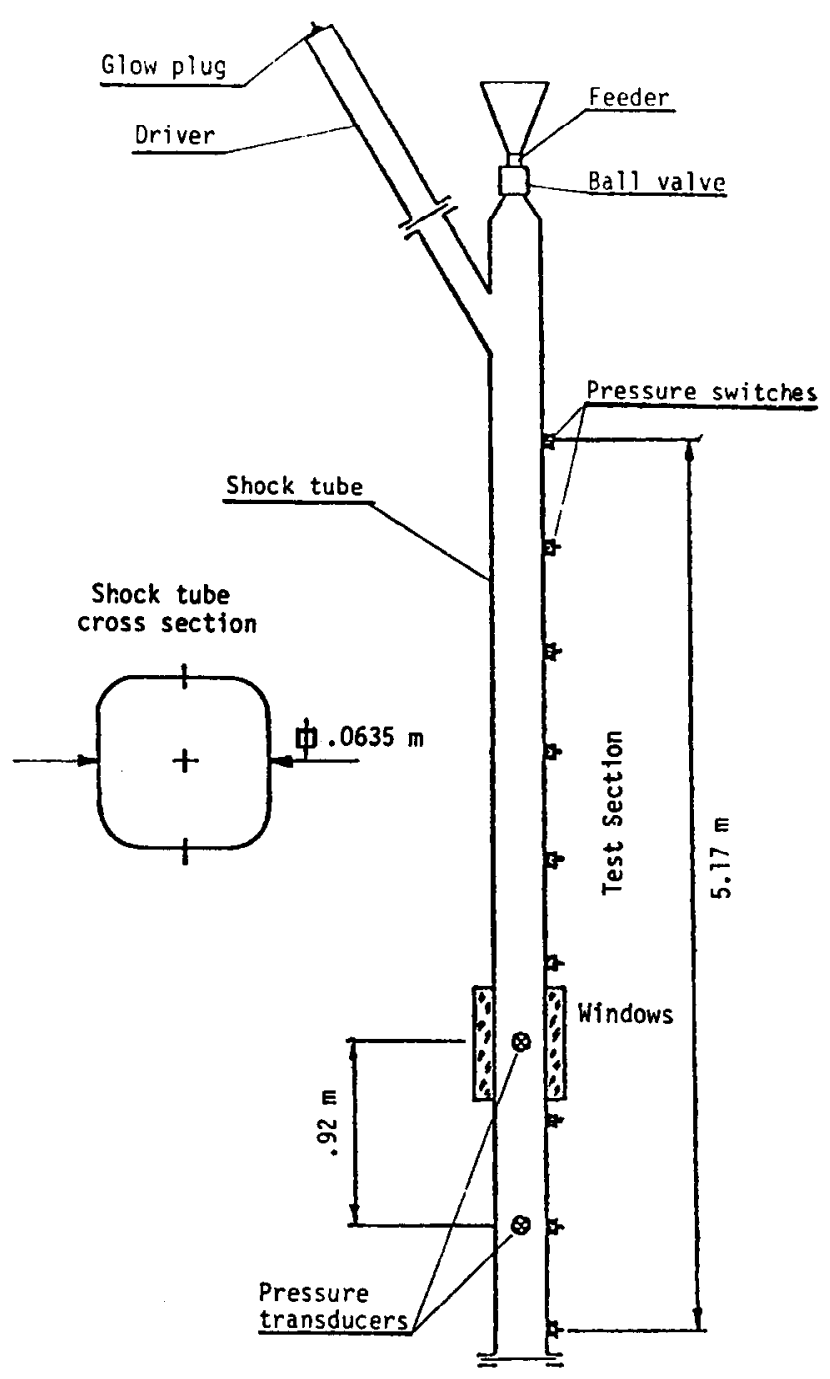

Fig. 23. Schematic diagram of the University of Michigan vertical detonation tube.

behind the shock wave, a bow shock associated with the particle is formed. The high temperature gases between the bow shock and particle cause rapid heating of the particle surface. Simultaneously the aerodynamic drag causes the particle to accelerate, thus reducing the gas temperature in the region between the bow shock and the particle and subsequently the rate of particle convective heating. Ignition occurs when the surface temperature increases to the critical value necessary for a fast chemical reaction on the surface which leads to ignition. The rate of particle heating depends on the particle size and properties. Very small particles can be heated more rapidly than larger ones, but the smaller particles rapidly accelerate to the convective flow velocity, so that the high temperature stagnation region will exist only for a short time. Larger particles accelerate more slowly but also absorb more heat prior to ignition. So one is led to the conclusion that there is an optimum particle diameter providing the most 


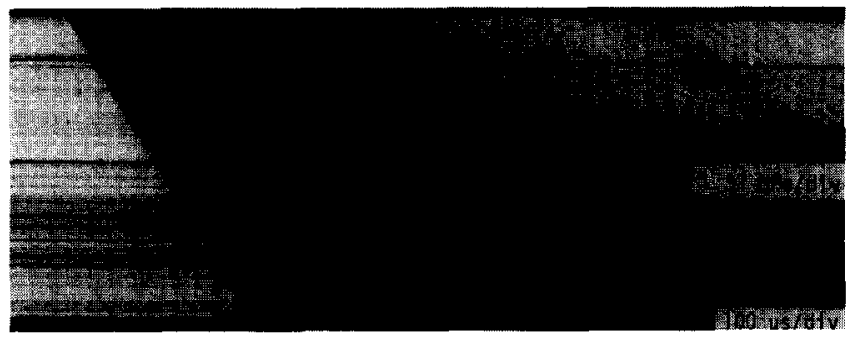

(a) Oats/air $V=1550 \mathrm{~m} \mathrm{~s}^{-1}, c=245 \pm 20 \mathrm{~g} \mathrm{~m}^{-3}$

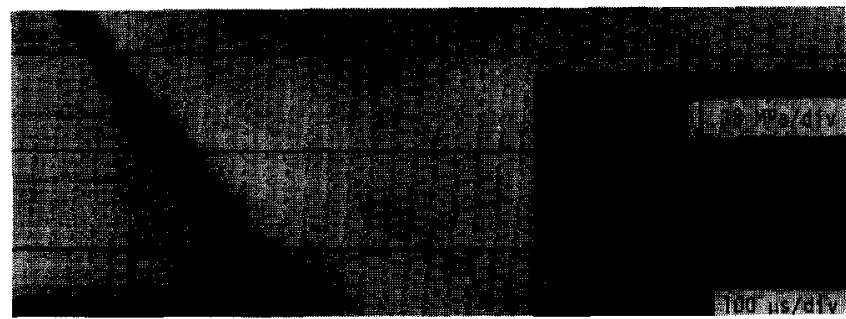

(b) Soybean/enriched air $V=1650 \mathrm{~m} \mathrm{~s}^{-1}, \mathrm{c}=315 \pm 25 \mathrm{~g} \mathrm{~m}^{-3}$

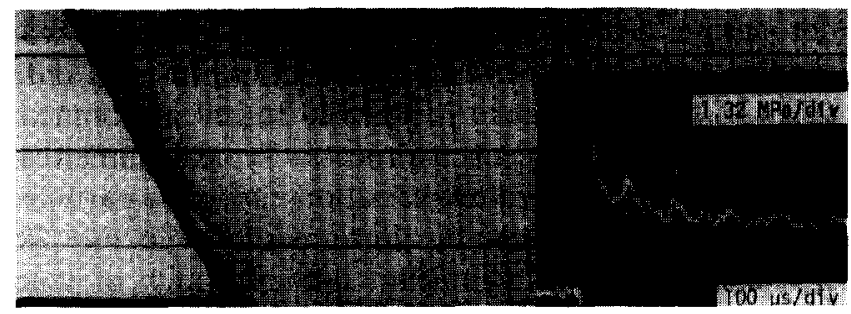

(c) Oats/oxygen $\mathrm{V}=1680 \mathrm{~m} \mathrm{~s}^{-1}, \mathrm{c}=305 \pm 25 \mathrm{~g} \mathrm{~m}^{-3}$

Fig. 24. Streak photographs and pressure traces of detonation wave in organic dust mixtures: (a) oats dust/air mixture, oats dust concentration: $0.245 \mathrm{~kg} \mathrm{~m}^{-3}$, detonation velocity: $1550 \mathrm{~m}$ $\mathrm{s}^{-1}$; (b) soybean dust $/ 40 \% / 60 \% \mathrm{O}_{2} / \mathrm{N}_{2}$ mixture, dust concentration: $0.315 \mathrm{~kg} \mathrm{~m}^{-3}$, detonation velocity: $1650 \mathrm{~m} \mathrm{~s}^{-1}$; (c) oat dust/ oxygen mixture, dust concentration: $0.305 \mathrm{~kg} \mathrm{~m}^{-3}$, detonation velocity: $1680 \mathrm{~m} \mathrm{~s}^{-1}$.

suitable conditions for ignition. Experimental data and detailed calculations confirm these expectations.

Numerical calculations also allow examination of some details of particle ignition which cannot be measured experimentally. It was found that during the ignition period only a very thin (a few microns) surface particle layer is heated to high temperature and reacts with the gaseous oxidizer. Below this layer the temperature remains nearly constant during the ignition. From this analysis it can be inferred that particles of irregular shape and of a porous nature will be more suitable for ignition than spherical or dense particles.

Ignition data obtained from shock tube experiments are very useful in evaluating the detonability of a dust mixture, since one finds that dust particles which are more readily ignited by incident shock waves are more likely to support detonative combustion.

When the shock wave interacts with a dust mixture different modes of combustion can be initiated. The combustion tront and shock wave can be separated, and the shock wave will decay to an acoustic wave and dust will burn in the deflagrative mode. A detonation wave may be created, i.e. a shock wave closely coupled with combustion. A quasi-detonation can be initiated, i.e. a combustion wave separated by a constant and distinct distance from the shock wave and traveling with velocity equal to the speed of sound for the combustion products. Finally, after initial separation of the combustion front from the shock wave, the flame may accelerate to a detonation (or quasi-detonation).

The quasi-detonation mode of dust mixture combustion was discussed in the previous section. It need only be added that quasi-detonation can be obtained by the process of self-acceleration (as in the FAT) or by shock wave initiation [19].

At the University of Michigan the vertical detonation tube was used for the direct initiation of detonation in mixtures containing dust, gases, and combinations thereof. A schematic diagram of this tube is shown in Fig. 23. The main tube is isolated from the initiator and the atmosphere by mylar diaphragms. Before an experiment the main tube can be evacuated and filled with the required mixture. The dust feeder supplies dust at a controllable rate, to produce the required dust concentration in the mixture. The initiator tube is filled with a gaseous explosive, usually a hydrogen/ oxygen/helium mixture. The initial pressure of the mixture can be varied to obtain different initiation energies. When the mixture in the main tube has been established the ball valve is closed to protect the feeder, the initiator is activated, and a blast wave is generated. The shock tube is equipped with pressure transducers, pressure switches, photodiodes, a microthermocouple, and a four colour pyrometer. The tube is also equipped with optical quality windows for direct and Schlieren visualization of the process. Detailed descriptions of this tube can be found elsewhere [13, 14, 46, 47].

Many experiments on direct initiation of a detonation in different organic dust mixtures were carried out. Typical Schlieren photographs of a dust detonation obtained in this tube are shown in Figs. 24, 25. In this tube, a detonation in air was obtained only for oats and wheat dust, but the addition of oxygen to air or running the experiments in pure oxygen allowed many more dust mixtures to be detonated. Detonability limits for air mixtures are obviously very narrow and very close to stoichiometric conditions. Oats dust will detonate in the concentration range $0.22-0.275 \pm 0.02 \mathrm{~kg}$ $\mathrm{m}^{-3}$ and wheat dust in the concentration range $0.25-0.305 \pm 0.03 \mathrm{~kg} \mathrm{~m}^{-3}$. Detonability limits for oats dust in air and in oxygen enriched air as a function of the stoichiometric coefficient are shown in Fig. 26.

In air the detonation velocity of wheat or oats dusts ranges from $1470 \mathrm{~m} \mathrm{~s}^{-1}$ to $1540 \mathrm{~m} \mathrm{~s}^{-1}$, with an average 


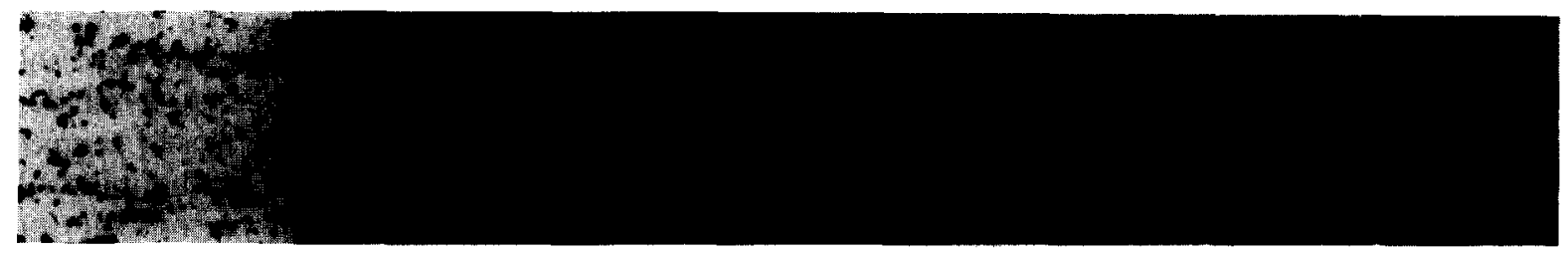

(a)

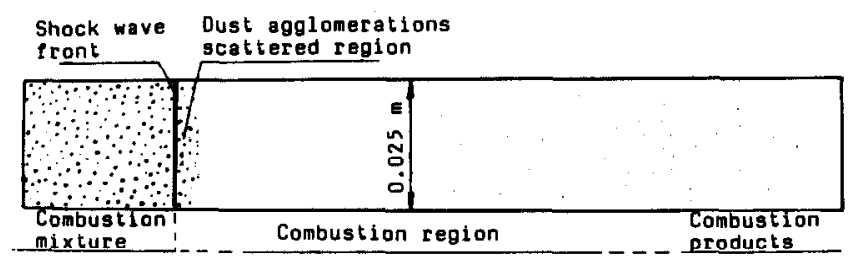

(b)

Fig. 25. Detonation of oats dust/air mixture, dust concentration: $0.25 \mathrm{~kg} \mathrm{~m}^{-3}$; detonation velocity: $1540 \mathrm{~m} \mathrm{~s}^{-1}$; (a) instantaneous laser schlieren photograph; (b) diagram of the picture.

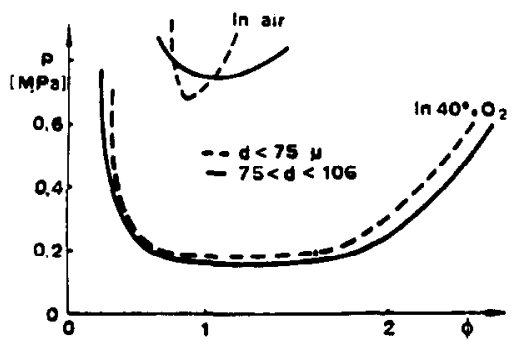

Fig. 26. Detonability range for the oats dust with different oxidizers.

value of $1500 \mathrm{~m} \mathrm{~s}^{-1}$. In oxygen, the maximum detonation velocity observed for organic dusts was close to 1800 $\mathrm{m} \mathrm{s}^{-1}$. In air mixtures the maximum pressure at the detonation front can reach 30 bars, and in oxygen up to 50 bars. For the region where the transition from deflagration to detonation occurs, a maximum pressure of 60 bars has been observed. The temperature of the burning dust particles in the detonation front was up to $2800 \mathrm{~K}$ in air, and slightly more than $3200 \mathrm{~K}$ in oxygen. Schlieren visualizations as well as pressure and temperature measurements allow evaluation of the basic features of the detonation wave structure. It was found for the given conditions that the detonation front thickness varied from $0.1 \mathrm{~m}$ for some oxygen mixtures to $0.8 \mathrm{~m}$ for some dust air detonations. The strong evidence of transverse waves was already reported in earlier studies [13].

Detailed numerical calculations reveal the structure and nature of dust detonations [47-49]. It was found that, just behind the shock, local oxidizer enrichment occurs which facilitates particle ignition. This is due to the very rapid compression of the gaseous phase and the relatively slow process of particle acceleration. Due to this the maximum shock pressure appears at a distinct distance behind the shock wave front. These peculiar features are due to the highly nonequilibrium condition existing between the gas and solid phase. Calculations of the one dimensional structure of a dust detonation, despite some simplifications, give very reasonable agreement with the limited experimental data (Fig. 27) and also make it possible to reveal nonmeasurable features of such a process. Typical numerical results for the temperature variation inside the particles during ignition and combustion are shown in Fig. 28. It can be seen that significant nonuniformity of temperature results during the ignition and initial stages of particle burning.

Research on the addition of combustible gas to the dust mixture was also carried out $[14,44]$. It was found that the addition of a small amount of a combustible gaseous mixture can significantly modify the detonation limits, and can even make it possible to detonate a

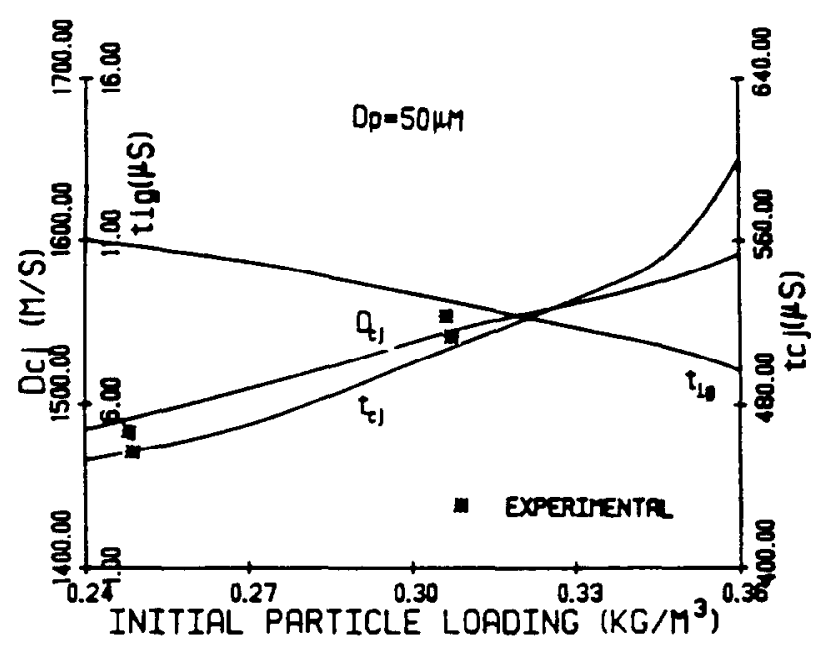

Fig. 27. Variations of the calculated ignition delay time, time for particles to reach $\mathrm{C}-\mathrm{J}$ conditions, and the detonation velocity, as a function of dust concentration for oats dust/air mixture. For comparison, the experimentally measured detonation velocity is indicated. 


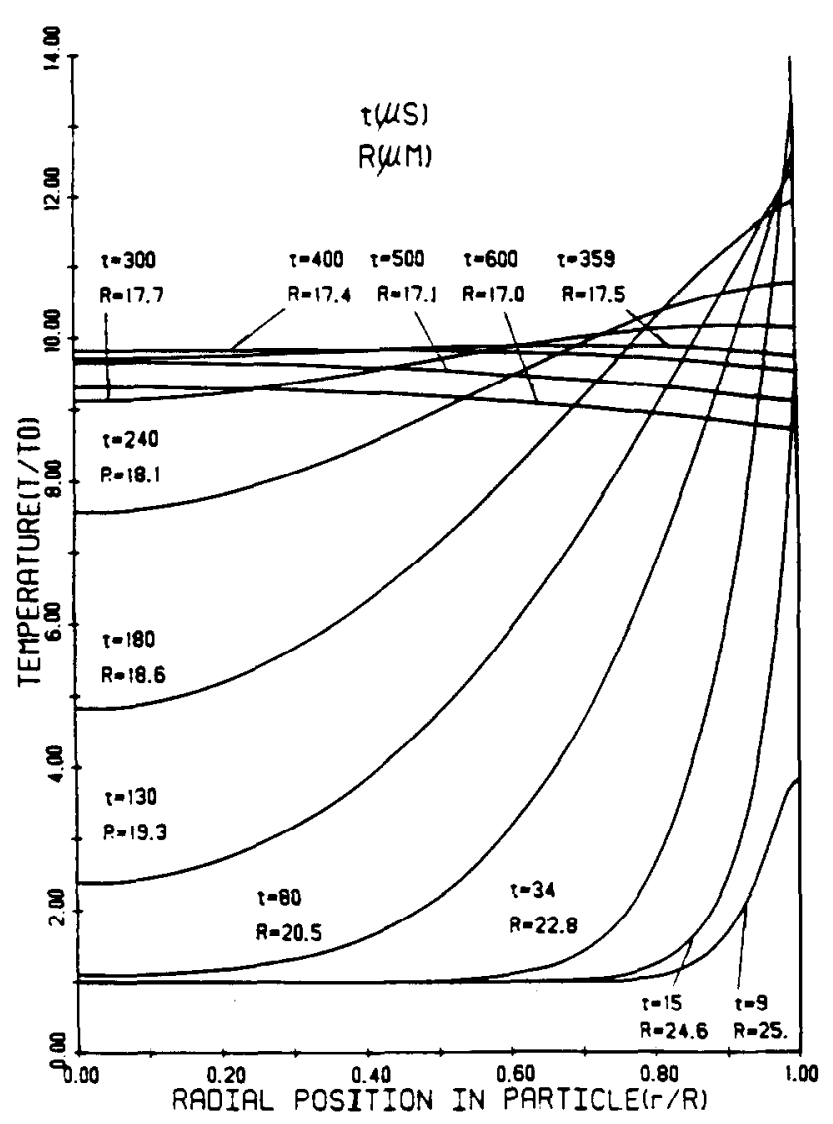

Fig. 28. Numerically calculated temperature variations within the burning particles in the detonation reaction zone.

mixture which could not be detonated without the added component. It was also found that the addition of nonreactive particles to the gaseous mixture can widen the lean detonability limit $[14,46,47]$, but the addition of inert particles to the gaseous mixtures always decreases the detonation velocity. The influence of nonreactive particles is always proportional to the specific volumetric particle surface area. A more detailed description of such effects can be found in [47] or in the recent survey paper on dust-related detonations [51].

Despite significant progress made here and in other laboratories, more experimental and theoretical research is necessary for better understanding of dust detonation phenomena.

\section{Conclusions}

At the University of Michigan a comprehensive research effort concerning dust explosions has been carried out for almost two decades. It covers the most important aspects of dust explosions, ranging from dust ignition, through smoldering combustion and turbulent com- bustion, to detonative combustion. The influence of the addition of a combustible gas to the dust mixture and of inert particles to combustible gaseous mixtures as well as their effect on detonative combustion has been studied.

Many commonly used dusts can be ignited relatively easily, can smolder and glow, burn with relatively high velocity, and even detonate. It has been found that there is an optimum size of particles suitable for shock wave ignition, and that a bimodal mixture can burn more violently than a mixture containing only small or large particles.

The combustion velocity of dust mixtures depends very much on the turbulence intensity and scale, so better understanding of the nature of turbulent combustion is essential for modelling all dust explosion phenomena. Recent experiments allow the dust burning velocity to be related to the turbulence intensity and scale, but research on turbulent dust combustion at high turbulence intensity and large scales is still essential for better understanding of fast dust flames and even quasi-detonation processes.

A very thin layer of dust can support explosive combustion in tubes. Flame acceleration due to layered dust combustion depends on the dust arrangement in the layer but even more strongly on the dust properties. Very fine and reactive dust can produce overpressures of up to 26 bars, and even transition to quasi-detonative combustion is possible.

Quasi-detonative and detonative combustion of some dust-air mixtures can propagate with a velocity ranging from $1000 \mathrm{~m} \mathrm{~s}^{-1}$ (for quasi-detonation) to nearly 1550 $\mathrm{m} \mathrm{s}^{-1}$ (for detonation), and with the addition of oxygen or in pure oxygen the propagation velocity can be even higher. The maximum pressure rise across the detonation front is usually much higher than in a deflagrative explosion, but the transition to detonation creates a higher pressure rise than the detonation itself.

In hybrid mixtures or in gaseous mixtures with the addition of nonreactive particles a widening of the detonability range, and a more rapid acceleration to detonation can be observed. However, the addition of inert or slowly reacting particles to gaseous mixtures decreases the detonation velocity, and they can eventually quench propagation.

Research on dust explosions carried out at the University of Michigan has improved understanding of many fundamental aspects of dust ignition, smoldering combustion, turbulent combustion, layered dust combustion, and detonations. Dust explosions are a very complex problem, and not all aspects of their initiation and propagation are completely understood, so further and more detailed experimental and theoretical studies of this problem are in progress in our laboratories. 


\section{References}

1 D. J. Price and H. H. Brown, Dust Explosions, National Fire Protection Association, Boston, MA, 1922.

2 K. N. Palmer, Dusts Explosions and Fires, Chapman and Hall, London, 1973.

3 W. Cybulski, Coal Dust Explosions and Their Suppression, U.S. Dept. of Commerce, National Technical Information Service, Springfield, VA, Warsaw, 1975.

4 W. Bartknecht, Explosions, Course, Prevention, Protection, Springer-Verlag, Berlin, Heidelberg, New York, 1981.

5 J. Nagy and H. C. Verakis, Development and Control of Dust Explosion, Marcel Dekker, New York and Basle, 1983.

6 M. Hertzberg and K. L. Cashdollar, Industrial Dust Explosions, ASTM STP 958, Philadelphia, 1987, pp. 5-32.

7 C. W. Kauffman, Fuel-Air Explosions, University of Waterloo Press, Waterloo, Ont., 1982, pp. 305-347.

8 C. W. Kauffman, Industrial Dust Explosions, ASTM STP 958, Philadelphia, 1987, pp. 243-264.

9 C. W. Kauffman and J. A. Nicholls, Fuel-Air Explosions, University of Waterloo Press, Waterloo, Ont., 1982, pp. 623-643.

10 P. Wolanski, Proc. Int. Symp. on Grain Dust, Division of Continuing Education, Kansas State University, Manhattan, KS, 1979, pp. 422-446.

11 P. Wolanski, First Specialists Meeting (International) of the Combustion Institute, American Institute of Aeronautics and Astronautics, Bordeaux, 1981, pp. 497-502.

12 P. Wolanski, Fuel-Air Explosions, University of Waterloo Press, Waterloo, Ont., 1982, pp. 979-981.

13 C. W. Kauffman, P. Wolanski, E. Ural, J. A. Nicholls and R. Van Dyk, Proc. Int. Symp. on Grain Dust, Division of Continuing Education, Kansas State University, Manhattan, KS, 1979, pp. 164-190.

14 C. W. Kauffman, P. Wolanski, A. Arisoy, P. R. Adams, B. N. Maker and J. A. Nicholls, Prog. Astronaut. Aeronaut., 94 (1984) 221.

15 B. R. Gardener, R. I. Winter and M. J. Moore, Twenty-First Int. Symp. on Combust., The Combustion Institute, Pittsburgh, PA, Munich, 1986.

16 P. Wolanski, Proc. Shenyang Int. Symp. on Dust Explosions, Shenyang, 1987, pp. 568-598.

17 A. A. Borisov, E. D. Saneev, S. V. Khomik, I. B. Fomin, B. A. Khasainov and B. Veyssière, Fourth Int. Colloq. on Dust Explosions, Porabka-Kozubnik, Poland, 1990.

18 R. Klemens, V. Johnston, C. Alexander, Y. Li, C. W. Kauffman and M. Sichel, Fourth Int. Colloq. on Dust Explosions, PorabkaKozubnik, Poland, 1990.

19 P. Wolanski, W. Sacha and M. Zalesinski, Fourth Int. Colloq. on Dust Explosions, Porabka-Kozubnik, Poland, 1990.

20 S. O. Leisch, Ph.D. Thesis, Dept. of Aerospace Engineering, the University of Michigan, Ann Arbor, MI, 1983 (also available from Xerox Corp., Ann Arbor, MI).

21 C. W. Kauffman, S. R. Srinath, F. I. Tezok, A. Arisoy and S. O. Leisch, First Int. Colloq. on Explosibility of Ind. Dusts, Baranow, Poland, 1984, p. 23.

22 J. Fangrat, C. W. Kauffman and M. Sichel, Fourth Int. Colloq. on Dust Explosions, Porabka-Kozubnik, Poland, 1990.

23 R. Klemens and P. Wolanski, Prog. Astronaut. Aeronaut., 105 (1986) 169.

24 I. Hartmann, A. R. Cooper and M. Jacobson, Rep. of Investigation 4725, U.S. Department of the Interior, Bureau of Mines, Washington, DC, 1951.
25 J. Nagy, J. W. Conn and H. C. Verakis, Rep. of Investigation 7279 , U.S. Department of the Interior, Bureau of Mines, Washington, DC, 1969.

26 J. Nagy, E. C. Seiler, J. W. Conn and H. C. Verakis, Rep. of Investigation 7507, U.S. Department of the Interior, Bureau of Mines, Washington, DC, 1971.

27 W. Buksowicz and P. Wolanski, Biul. Inf. Tech. KGSP, 3-4, (1980) 87 (in Polish).

28 F. I. Tezok, Ph.D. Thesis, Dept. of Aerospace Engineering, the University of Michigan, Ann Arbor, MI, 1985.

29 G. E. Andrews and D. Bradley, Combust. Flame, 19 (1972) 133.

30 D. Bradley and A. Michelson, Combust. Flame, 26 (1976) 201.

31 Y. C. Li, Y. K. Pu, C. W. Kauffman, L. P. Bernal and V. G. Johnston, Prog. Astronaut. Aeronaut., 132 (1991) 107.

32 S. R. Srinath, C. W. Kauffman, J. A. Nicholls and M. Sichel, Industrial Dust Explosions, ASTM STP 958, Philadelphia, 1987, pp. 90-106.

33 C. Bai and C. W. Kauffman, Annual Technical Meeting, Eastern States Section of the Combustion Institute, Cornell University, Ithaca, NY, November 1991.

34 S. R. Srinath, C. W. Kauffman, J. A. Nicholls and M. Sichel, Prog. Astronaut. Aeronaut., 105 (1986) 196.

35 C. W. Kauffman, S. R. Srinath, F. I. Tezok, J. A. Nicholls and M. Sichel, Twentieth Int. Symp. on Combust., The Combustion Institute, Pittsburgh, 1985, pp. 1701-1708.

36 C. W. Kauffman, Third Int. Colloq. on Dust Explosions, Institute of Heat Engineering of the Warsaw Technical University, Szczyrk, Poland, 1988.

37 D. N. Chi and H. E. Perlee, RI 7908, U.S. Department of the Interior, Bureau of Mines, Pittsburgh, PA, 1974.

38 S. R. Srinath, Ph.D. Thesis, Department of Aerospace Engineering, the University of Michigan, Ann Arbor, MI, 1985.

39 H. Mirels, ALAA J., 22 (1984) 1582.

40 D. P. Clark and L. D. Smoot, Combust. Flame, 62 (1985) 255.

41 T. W. Fox, C. W. Rackett and J. A. Nicholls, Proc. 11th Int. Symp. on Shock Tubes and Waves, The University of Washington Press, Seattle, WA, 1977, pp. 262-268.

42 E. Ural, Ph.D. Thesis, the University of Michigan, Ann Arbor, MI, 1981 (also available from Xerox Corp., Ann Arbor, MI).

43 M. Sichel, S. W. Baek, C. W. Kauffman, B. Maker, J. A. Nicholls and P. Wolanski, AIAA J., 23 (1985) 1374.

44 C. W. Kauffman, J. A. Nicholls and P. Wolanski, Second National Workshop on Explosibility of Industrial Dusts, Czestochowa, Poland, 10-12 November 1980, also Biul. Inf. Tech. KGSP, 3-4 (1980) 12 (in Polish).

45 F. P. Lee, C. W. Kauffman, M. Sichel and J. A. Nicholls, ALAA J., 24 (1986) 1811.

46 M. Wolinski, P. Wolanski, R. M. Myers, C. W. Kauffman, M. Sichel and J. A. Nicholls, Ninth Int. Pyrotechnics Semin., Colorado Springs, CO, 1984, pp. 861-872.

47 P. Wolanski, J. C. Liu, C. W. Kauffman, J. A. Nicholls and M. Sichel, Arch. Combustionis, 8 (1988) 15.

48 P. Wolanski, D. Lee, M. Sichel, C. W. Kauffman and J. A. Nicholls, Prog. Astronaut. Aeronaut., 94 (1984) 241.

49 D. Lee and M. Sichel, Prog. Astronaut. Aeronaut., 106 (1986) 505.

50 B. C. Fan and M. Sichel, Twenty-Second Int. Symp. on Combustion, The Combustion Institute, 1988, pp. 1741-1750.

51 C. W. Kauffman, M. Sichel and P. Wolanski, in A. A. Borisov (ed.), Dynamic Structure of Detonations in Gaseous and Dispersed Media, Kluwer Academic, 1991, pp. 267-311. 